\title{
Assimetria e concentração: \\ um estudo empírico da distribuição de investimentos \\ previstos para o Estado do Espírito Santo, 2009-2014
}

\author{
Matheus Albergaria de Magalhães \\ Instituto Jones dos Santos Neves (IJSN) \\ Victor Nunes Toscano \\ Instituto Jones dos Santos Neves (IJSN)
}

\section{Palavras-chave \\ economia regional, \\ investimento, Lei de Zipf, \\ Espírito Santo.}

Classificação JEL C16, R12, R53.

\section{Key words}

regional economics, investment, Zipf's Law, Espirito Santo.

JEL Classification $C 16, R 12$, $R 53$.

\section{Resumo}

Realizar um detalhado estudo empírico descritivo de uma distribuição de projetos de investimento regionais destinados ao Estado do Espírito Santo é o objetivo deste trabalho. Para tanto, é feita uma análise valendose de uma base de dados inédita, contendo 972 projetos de investimentos previstos para distintas localidades espírito-santenses, ao longo do período 2009-2014. Adicionalmente, o trabalho busca verificar a validade empírica da Lei de Zipf para esta distribuição de investimentos. Em termos gerais, os resultados obtidos são importantes no sentido de facilitar a identificação de padrôes empíricos referentes à distribuição do investimento no espaço, podendo ser úteis em termos de formulação e implementação de políticas públicas voltadas para o desenvolvimento de localidades específicas.

\section{Abstract}

This paper aims to provide a detailed statistical descriptive analysis for the distribution of regional investments. In doing so, it used a novel dataset related to planned investment projects for Espirito Santo's municipalities during the 2009-2014 period. Additionally, we present results related to these investment values in order to test the empirical validity of Zipf's Law for the distribution under analysis. These results are important for the identification of empirical patterns related to the spatial distribution of investment projects, and may be useful for the formulation and implementation of public policies aimed at developing specific localities. 


\section{1_Introdução}

Compreender a distribuição de projetos de investimento constitui um importante desafio em termos de políticas públicas. Em particular, características específicas da distribuição estatística dos investimentos relacionados a uma localidade podem revelar significativos padróes empíricos, úteis tanto no sentido de auxiliar na formulação e na implementação de políticas regionais quanto no sentido de constituir base para a elaboração de modelos teóricos relacionados ao comportamento dessa variável econômica. ${ }^{1}$

Por conta disso, o principal objetivo deste trabalho equivale a uma análise estatístico-descritiva da distribuição de projetos de investimento regionais. A presente análise baseia-se nos resultados divulgados pelo Instituto Jones dos Santos Neves (IJSN), valendo-se da pesquisa "Investimentos Previstos no Espírito Santo: 2009-2014". ${ }^{2}$ Essa pesquisa corresponde a uma tentativa de sistematizar informações oriundas de distintas fontes, relacionadas a projetos de investimento anunciados para os municípios e as microrregióes administrativas do Estado. ${ }^{3}$ Especificamente, tal pesquisa apresenta a particularidade de englobar a ampla maioria dos projetos de investimento anunciados para o Espírito Santo para os próximos cinco anos. A partir da descri- ção de alguns dos principais resultados relacionados a essa pesquisa, espera-se chamar a atenção para possíveis potenciais de aplicaçóes relacionadas a essa base de dados.

Adicionalmente, este trabalho busca verificar a adequação empírica da Lei de Zipf aos projetos de investimento previstos para o Estado ao longo do período em análise. Para tanto, são utilizadas informações referentes a esses projetos de investimento cobrindo o território espírito-santense, assim como são realizados testes estatísticos buscando verificar a validade da lei supracitada. Em consonância com a literatura relacionada a testes dessa lei no contexto de Economia Urbana (tamanho de cidades, basicamente), espera-se que, a partir desse esforço de pesquisa, seja possível a obtenção de explicaçóes relacionadas ao formato da distribuição dos projetos de investimento, bem como sua hierarquia em termos

\footnotetext{
2 Para mais detalhes sobre essa pesquisa, ver Taveira et al. (2010).

3 Atualmente, o Estado do Espírito Santo está dividido em 78 municípios, havendo quatro macrorregiōes de planejamento e 12 microrregióes administrativas. A este respeito, ver o Apêndice $A$ do presente trabalho.
} 
${ }^{4}$ A referência original sobre o tema equivale a Zipf (1949). Para exemplos de estudos empíricos relacionados a essa lei, ver a seção de referencial teórico do presente trabalho.

5 Um breve estudo da evolução dos investimentos na indústria brasileira, ao longo do período 2010-2013, está contido em Puga e Meirelles (2010). Para uma detalhada análise dos grandes projetos de investimento relacionados ao Estado do Espírito Santo, ver Iglesias (2010). de valores. Alternativamente, o presente trabalho pode ser visto como a verificação da adequação empírica da Lei de Zipf em um contexto distinto do usual. ${ }^{4}$

Uma vantagem de um empreendimento nesses moldes equivale ao fato de ser possível, com base em um estudo descritivo da distribuiçấo de projetos de investimentos previstos, melhor compreensão da dinâmica do investimento regional em termos espaciais, uma vez que a base de dados analisada compreende projetos referentes aos municípios do Estado do Espírito Santo. Em última instância, a importância do tema reside no fato de que, a partir dos resultados de exercícios empíricos aqui descritos, passa a ser possível a identificação de padrôes referentes a essas projeçôes de investimento, com implicaçóes diretas em termos de planejamento e implementação de políticas regionais de desenvolvimento. ${ }^{5}$

O trabalho está dividido da seguinte maneira: a segunda seção apresenta breve caracterização econômica do Estado do Espírito Santo, enquanto a terceira seção contém definiçôes relacionadas às Leis de Pareto e de Zipf. A quarta seção, por sua vez, apresenta uma revisão parcial da literatura relacionada à importância de investimentos regionais e às aplicaçóes das Leis de Zipf e Pareto em distintos contextos. A quinta se- ção descreve a base de dados empregada no trabalho, ao passo que a sexta apresenta os principais resultados da análise empírica conduzida. A sétima seção descreve testes de robustez relacionados aos principais resultados obtidos. Finalmente, a oitava seção apresenta conclusôes e algumas sugestóes de pesquisa futura sobre o tema.

\section{2_Caracterização econômica do Estado do Espírito Santo}

Esta seção do trabalho relata breve caracterização da economia do Estado do Espírito Santo como forma de motivar melhor o tema, assim como apresentar algumas das peculiaridades da estrutura produtiva local.

A Tabela 1 mostra valores referentes ao Produto Interno Bruto (PIB) a preços correntes (em milhóes de reais) do Brasil (primeira coluna) e do Espírito Santo (segunda coluna). A título de comparação, a terceira coluna exibe valores correspondentes à razáo entre os dados da segunda e primeira coluna. $\mathrm{O}$ objetivo principal dessa operação é captar a participaçáo relativa da economia estadual na economia nacional.

Os resultados apontam para um cenário no qual, apesar de pequena, a participação do Espírito Santo no PIB 
Tabela 1_Produto Interno Bruto (PIB) a preços correntes (R\$ 1.000.000) Brasil e Espírito Santo, 2002-2008

Produto Interno Bruto a preços correntes (R\$ 1.000.000)

\begin{tabular}{|c|c|c|c|}
\hline Ano & Brasil (1) & Espírito Santo (2) & $\begin{array}{c}\text { Participação (\%) } \\
\text { ES-BR (2)/(1) }\end{array}$ \\
\hline 2002 & 1.477 .822 & 26.756 & 1,81 \\
\hline 2003 & 1.699 .948 & 31.064 & 1,83 \\
\hline 2004 & 1.941 .498 & 40.217 & 2,07 \\
\hline 2005 & 2.147 .239 & 47.223 & 2,2 \\
\hline 2006 & 2.369 .484 & 52.778 & 2,23 \\
\hline 2007 & 2.661 .345 & 60.340 & 2,27 \\
\hline 2008 & 3.031 .864 & 69.870 & 2,3 \\
\hline
\end{tabular}

Fonte: Cálculos dos autores, com base em dados do IBGE.

brasileiro vem exibindo padrão crescente e contínuo ao longo do período 20022008, tendo aumentado de $1,8 \%$, no ano de 2002, para 2,3\%, em 2008 (último dado disponível). Durante esse período, a participação média e mediana $\mathrm{da}$ economia estadual ficou em torno de $2,1 \%$ e $2,2 \%$, respectivamente, o que confirma a representatividade da participação em questão.

A Tabela 2, por sua vez, apresenta dados referentes ao PIB per capita das Unidades da Federação (UFs), com ênfase nas dez primeiras colocadas em um ranking decrescente de valores. A intenção básica, no caso, equivale a ressaltar a evolução do nível de bem-estar (medido via PIB per capita) no Estado do Espírito Santo, no período 2002-2008.

De acordo com os resultados reportados na tabela, pode-se notar clara evolução da colocação do Estado no ranking das UFs no período analisado. Em particular, observa-se que o ES saiu da oitava colocação em 2003 para a quinta colocação em 2005, tendo até alcançado a quarta colocação em 2007. Apesar das limitaçóes inerentes a essa medida de bem-estar, os resultados supracitados apontam para um padrão de evolução da economia estadual no contexto nacional. ${ }^{6}$

\footnotetext{
6 Vale a ressalva, conforme atentado por Caçador e Grassi (2009), que, apesar de o Estado do Espírito Santo vir exibindo taxas de crescimento superiores à média nacional desde a década de 90, indicadores referentes à área de Ciência e Tecnologia (C\&T) ainda apontam para uma situação de atraso relativo, resultado que pode vir a comprometer o desempenho da economia local no longo prazo. Mais detalhes adiante.
} 
Tabela 2_"Ranking" do PIB "per capita" nas Unidades da Federação (UFs), 2002-2008

\begin{tabular}{|c|c|c|c|c|c|c|c|}
\hline Posição & 2002 & 2003 & 2004 & 2005 & 2006 & 2007 & 2008 \\
\hline 1 & $\begin{array}{l}\text { Distrito } \\
\text { Federal }\end{array}$ & $\begin{array}{l}\text { Distrito } \\
\text { Federal }\end{array}$ & $\begin{array}{l}\text { Distrito } \\
\text { Federal }\end{array}$ & $\begin{array}{l}\text { Distrito } \\
\text { Federal }\end{array}$ & $\begin{array}{l}\text { Distrito } \\
\text { Federal }\end{array}$ & $\begin{array}{l}\text { Distrito } \\
\text { Federal }\end{array}$ & $\begin{array}{l}\text { Distrito } \\
\text { Federal }\end{array}$ \\
\hline 2 & São Paulo & São Paulo & São Paulo & São Paulo & São Paulo & Sáo Paulo & São Paulo \\
\hline 3 & Rio de Janeiro & Rio de Janeiro & Rio de Janeiro & Rio de Janeiro & Rio de Janeiro & Rio de Janeiro & Rio de Janeiro \\
\hline 4 & $\begin{array}{c}\text { Rio Grande } \\
\text { do Sul }\end{array}$ & Santa Catarina & Mato Grosso & Santa Catarina & Santa Catarina & Espírito Santo & Santa Catarina \\
\hline 5 & Santa Catarina & $\begin{array}{c}\text { Rio Grande } \\
\text { do Sul }\end{array}$ & Santa Catarina & Espírito Santo & Espírito Santo & Santa Catarina & Espírito Santo \\
\hline 6 & Paraná & Paraná & $\begin{array}{c}\text { Rio Grande } \\
\text { do Sul }\end{array}$ & Mato Grosso & $\begin{array}{c}\text { Rio Grande } \\
\text { do Sul }\end{array}$ & $\begin{array}{c}\text { Rio Grande } \\
\text { do Sul }\end{array}$ & $\begin{array}{c}\text { Rio Grande } \\
\text { do Sul }\end{array}$ \\
\hline 7 & Espírito Santo & Mato Grosso & Paraná & $\begin{array}{c}\text { Rio Grande } \\
\text { do Sul }\end{array}$ & Paraná & Paraná & Mato Grosso \\
\hline 8 & Mato Grosso & Espírito Santo & Espírito Santo & Paraná & Mato Grosso & Mato Grosso & Paraná \\
\hline 9 & Amazonas & $\begin{array}{l}\text { Mato Grosso } \\
\text { do Sul }\end{array}$ & Amazonas & Amazonas & Amazonas & Amazonas & Minas Gerais \\
\hline 10 & Goiás & Amazonas & $\begin{array}{l}\text { Mato Grosso } \\
\qquad \text { do Sul }\end{array}$ & Minas Gerais & Minas Gerais & Minas Gerais & $\begin{array}{l}\text { Mato Grosso } \\
\text { do Sul }\end{array}$ \\
\hline
\end{tabular}

Fonte: Cálculos dos autores, com base em dados do IBGE.

Por outro lado, em termos de comércio exterior, vale notar que o Espírito Santo pode ser caracterizado como um dos estados com maior grau de abertura do país. Distintos estudos destinados a mensurar o grau de abertura do Estado chegaram à mesma conclusão em relação a sua posição perante a outras UFs, embora possam ser destoantes em termos de magnitude do coeficiente de abertura propriamente dito, provavelmente decorrente de diferenças relacionadas a períodos de análise e/ou metodologia empregados. A Tabela 3 resume alguns dos estudos relacionados ao tema e as respectivas estimativas de grau de abertura para a economia estadual. 
Tabela 3_Estimativas de Grau de Abertura (G.A.) para o Estado do Espírito Santo, de acordo com distintos estudos empíricos

\begin{tabular}{|c|c|c|c|c|}
\hline Autores & Período amostral & Frequência temporal & Estimativa G.A. & Posição "ranking" \\
\hline Souza (2003) & $1991 / 2000$ & Anual & $60,8 \%$ & $1^{o}$ \\
\hline Magalhães e Toscano (2010a) & 2004:01/2009:02 & Trimestral & $48,7 \%$ & n.c. \\
\hline Pereira e Maciel (2010) & $2000 / 2006$ & Anual & $50,3 \%$ & $1^{\mathrm{o}}$ \\
\hline
\end{tabular}

Fontes: Souza (2003), Magalhăes e Toscano (2010a) e Pereira e Maciel (2010).

Nota: (a) O termo "n.c." denota "nada consta". No caso do trabalho de Magalháes e Toscano (2010b), os autores năo elaboraram um ranking de coeficientes de abertura das UFs, uma vez que trabalham apenas com dados referentes ao Estado do Espírito Santo e ao Brasil.

Quanto a sua pauta de exportaçóes, o Espírito Santo pode ser caracterizado principalmente como um Estado exportador de bens básicos e intermediários. A Tabela 4 contém dados que corroboram essa última afirmação, uma vez que apresenta a participação percentual dos bens exportados e importados pelo Estado, classificados por fator agregado.

Os dados da Tabela 4 demonstram que cerca de metade das exportações do Espírito Santo (47,3\%) equivale a produtos básicos, enquanto, no caso das importaçóes, a ampla maioria dos bens

Tabela 4_Participação percentual de bens (classificação por fator agregado) nas exportações e importações do Estado do Espírito Santo, 2009

\begin{tabular}{|c|c|c|}
\hline & Exportações & Importações \\
\hline Básicos & 47,29 & 5,49 \\
\hline Manufaturados & 21,94 & 88,87 \\
\hline Semimanufaturados & 28,23 & 5,65 \\
\hline Consumo de bordo & 2,54 & - \\
\hline
\end{tabular}

Fonte: Magalhāes (2011)

Nota: (a) O termo "Consumo de bordo" serve para denotar o conjunto de bens transacionados entre residentes e não residentes a bordo de aeronaves, embarcaçôes, etc.?

\footnotetext{
Para mais detalhes a respeito dessa informação, ver o website do Banco Central do Brasil (http://www.bcb.gov.br/ ftp/infecon/BalPagSet_P.pdf).
} 


\section{Gráfico 1_Componentes cíclicos de índices de produção industrial do Brasil e do Espírito Santo, 1991:01/2009:02 (dados trimestrais)}

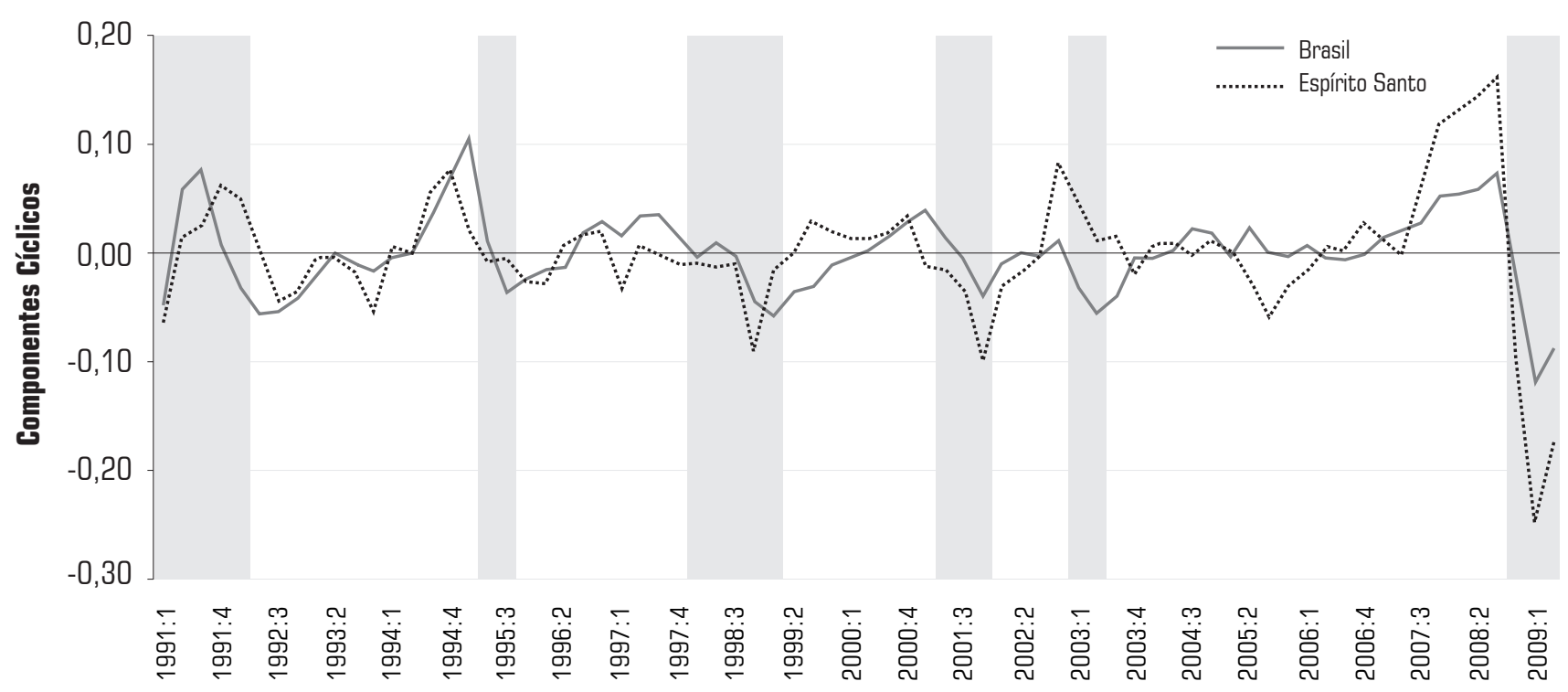

Ano: Trimestre

Fonte: Magalhães e Ribeiro (2011, Gráfico 3, p.606).

Notas:

(1) Os dados utilizados no gráfico acima possuem periodicidade trimestral, englobando o período 1991:01/2009:02. Todos os dados estão em escala logarítmica, com seus componentes cíclicos tendo sido obtidos com base no filtro Hodrick-Prescott, considerando $\lambda=1600$.

(2) Áreas em cinza equivalem a períodos de recessão na economia brasileira, em consonância com a cronologia desenvolvida pelo Comitê de Datação dos Ciclos Econômicos (CODACE).

transacionados corresponde a bens manufaturados (89\%). A princípio, pode-se notar a ocorrência de nítidas diferenças entre os bens importados e exportados pelo Estado em termos de sofisticação tecnológica, o que evidencia fragilidades da economia local relacionadas a suas atividades de comércio exterior.
Por conta de seu alto grau de abertura e pelo elevado grau de concentração de sua pauta de exportaçóes, o Espírito Santo apresenta, em geral, maior volatilidade relativa em suas flutuações econômicas em comparação ao Brasil e às demais UFs. O Gráfico 1 descreve a evolução dos componentes cíclicos (obtidos via filtro 


\section{Gráfico 2_Volatilidade das séries de produção industrial - Brasil e Espírito Santo (dados trimestrais)}
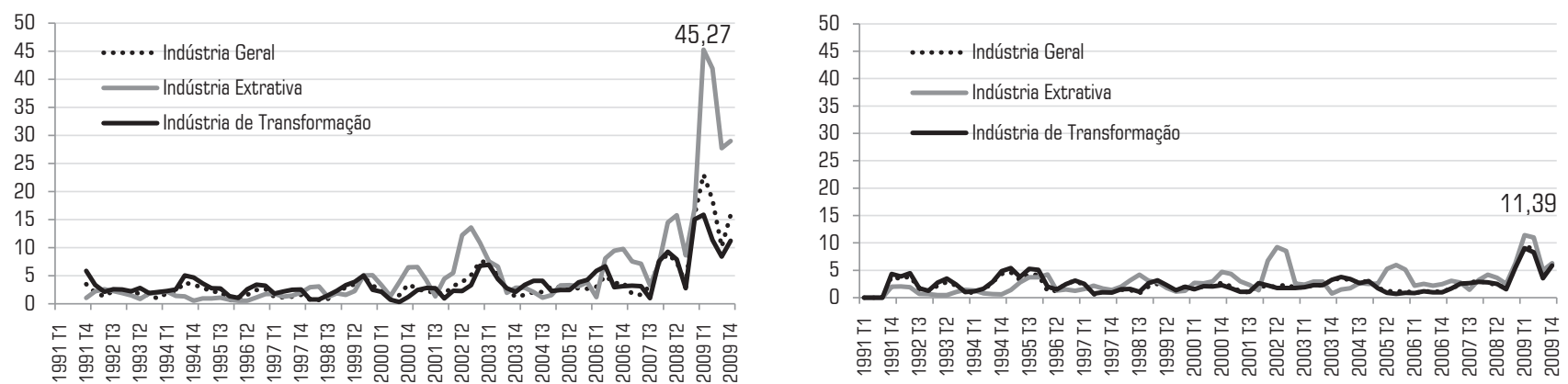

Fonte: Panorama Econômico (2009).

Hodrick-Prescott) das séries de produção industrial do Brasil e do Espírito Santo, ao longo do período 1991:01/2009:02 (dados trimestrais). Adicionalmente, esse gráfico expóe as recessôes ocorridas no país, durante esse período, em consonância com a cronologia criada pelo Comitê de Datação dos Ciclos Econômicos (CO$\mathrm{DACE})$, e correspondentes às áreas em cinza do gráfico (Conjuntura Econômica 2009).

O padráo gráfico reportado acima permite inferir dois fatos: primeiro, os ciclos das séries de produção industrial nacional e estadual apresentam padrão contracionista ao longo da maior parte das recessóes ocorridas no país, embora não haja perfeito padrão de sincronia; segundo, nota-se maior volatilidade relativa dos ciclos industriais do Estado, em comparação aos ciclos do país, especialmente no caso dos últimos períodos da amostra considerada.

O Gráfico 2 confirma a maior volatilidade relativa da economia estadual em comparação à economia nacional no caso do uso de distintos índices de produção industrial. Nesse gráfico estão expostos os desvios-padrão das séries temporais dos índices correspondentes às indústrias Geral, Extrativa e de Transformação, tanto no caso do Espírito Santo (gráfico à esquerda) quanto no caso do Brasil (gráfico à direita). Para facilitar a comparação dessas séries, as escalas de ambos os gráficos foram padronizadas. ${ }^{8}$

Mais uma vez, é possível constatar a ocorrência de um padrão mais volátil no caso espírito-santense, com a indústria extrativa estadual tendo alcançado um va-
${ }^{8}$ Esses gráficos foram construídos com base no cálculo de medidas de desviospadrão em janelas móveis de quatro trimestres. 
9 Uma característica adicional da economia local equivale à ocorrência de nítidos padróes de concentração espacial, seja em termos de investimentos, PIB per capita, seja em termos de população. Para mais detalhes a respeito da ocorrência desses padróes, ver as próximas seções do presente trabalho.

10 As derivações abaixo são baseadas em Gabaix (2008) e Gabaix e Ioannides (2004). lor máximo de $45,27 \%$ em seu desvio-padrão, no primeiro trimestre de 2009, valor cerca de quatro vezes superior ao valor reportado para a mesma indústria em âmbito nacional $(11,39 \%)$.

Em suma, os resultados reportados nesta seção demonstram que a economia do Espírito Santo pode ser caracterizada como uma pequena economia aberta, dado seu alto grau de abertura ao comércio exterior e à concentraçáo de suas exportações em bens básicos e intermediários, o que, por sua vez, faz com que sofra oscilaçóes mais voláteis no curto prazo. ${ }^{9}$

A análise subsequente toma como base esses resultados relacionados à estrutura produtiva local para a caracterização empírica da distribuição de investimentos previstos no Espírito Santo, no período de 2009-2014. Antes, no entanto, a próxima seção apresenta algumas definições relacionadas a distribuições de cauda longa.

\section{3_ Leis de Pareto e Zipf}

Algumas regularidades empíricas em economia podem ser representadas valendose de leis de potências (power laws). ${ }^{10}$ Formalmente, leis desse tipo podem ser representadas a partir da seguinte fórmula matemática:

$$
Y=k X^{\alpha}
$$

onde os termos $Y$ e $X$ representam variáveis de interesse, enquanto $k$ equivale a uma constante. Por sua vez, o termo $\alpha$ denota o expoente que governa a lei de potência em questão. Leis de potências apresentam diversas aplicaçóes em economia. Por exemplo, leis dessa natureza podem ser utilizadas para modelar fenômenos como distribuição de renda, tamanho de cidades e firmas, retornos de açóes e volumes negociados em bolsas de valores (Adamic, 2002; Gabaix, 2008).

Em particular, um tipo especial de lei de potência equivale à Lei de Pareto, que pode ser representada a partir da seguinte expressão:

$1 / X^{\zeta}$

Em relação à última fórmula, o termo $\zeta$ exerce a mesma função que o termo $\alpha$ exercia na fórmula (1), sendo o parâmetro que governa a Lei de Pareto.

Por exemplo, pode-se expor a probabilidade de que uma dada firma tenha um número de funcionários superior a um valor arbitrário $x$ a partir da fórmula abaixo:

$$
\operatorname{Prob}(S>x)=k / x^{\zeta}
$$

com essa fórmula sendo válida para alguma constante $k$, pelo menos na parte superior da distribuição de firmas da economia. 
Duas observações devem ser feitas em relação à última fórmula: primeiro, o expoente $\zeta$ dessa expressão independe da unidade de medida em que a Lei de Pareto é expressa; segundo, no caso onde $\zeta=1$, obtém-se a Lei de Zipf, que nada mais é do que uma particularidade da Lei de Pareto. ${ }^{11}$

No que concerne ao presente contexto, essas ideias podem ser expressas tendo em vista a seguinte formalização. Seja $S_{i}$ o valor de um dado projeto de investimento. Basicamente, diz-se que os valores desses projetos satisfazem a Lei de Zipf se, no caso de um dado valor maior $S$, valer a seguinte relação:

$$
\operatorname{Prob}(\text { Tamanho }>S)=a / S^{\zeta}
$$

A respeito dessa fórmula, o termo $a$ equivale a uma constante positiva $(a>$ 0 ), e o termo $\zeta$ equivale a um parâmetro que pode assumir valor maior, igual ou menor que a unidade. Em particular, caso $\zeta=1$, tem-se a validade empírica da Lei de Zipf (ou seja, o produto entre valor e ranking de um investimento equivale a uma constante). Caso $\zeta$ seja maior que 1 , diz-se que a hierarquia dos investimentos tende a ser mais igualitária, isto é, investimentos de menor valor estão, em média, mais próximos de investimentos de maior valor. Por outro lado, situaçóes nas quais $\zeta$ é menor que 1 equivalem a cenários correspondentes a uma hierarquia de investimentos mal distribuída, com a maior parte dos valores concentrando-se em poucos projetos, geralmente os primeiros colocados no ranking de valores. Em termos gerais, o parâmetro $\zeta$ estimado pode vir a gerar inferências úteis sobre a hierarquia dos projetos de investimento previstos para o Estado. ${ }^{12}$

Uma maneira alternativa de se enunciar a Lei de Zipf equivale a dizer que o valor dos projetos segue a chamada "rank size rule"; ou seja, caso os projetos de investimento sejam classificados em ordem decrescente de tamanho, pode-se observar a seguinte regularidade empírica: o segundo projeto nesse ranking teria metade do valor do projeto que ocupa o primeiro lugar no ranking; o terceiro teria um terço desse valor, e assim por diante. Empiricamente, esse padrão poderia ser exibido a partir do seguinte gráfico, descrito no Gráfico 3 e relacionado ao tamanho de cidades americanas.

O Gráfico 3 equivale a um diagrama de dispersão relacionando o tamanho de cidades com suas respectivas posições em um ranking decrescente de tamanho (ambas as variáveis estão expressas em escala logarítmica natural), no caso das 135 maiores áreas metropolitanas dos Estados Unidos, durante 1991 (Gabaix, 1999, p.
11 Sobre a equivalência das Leis de Pareto e Zipf, ver Adamic (2002).

${ }^{12}$ No limite, em uma situação onde $\zeta=\infty$, todos os investimentos teriam os mesmos valores, o que denotaria perfeita hierarquia dos projetos em questáo. 
Gráfico 3_Diagrama de dispersão entre populações de cidades e suas respectivas posições no "ranking", áreas metropolitanas dos Estados Unidos, 1991

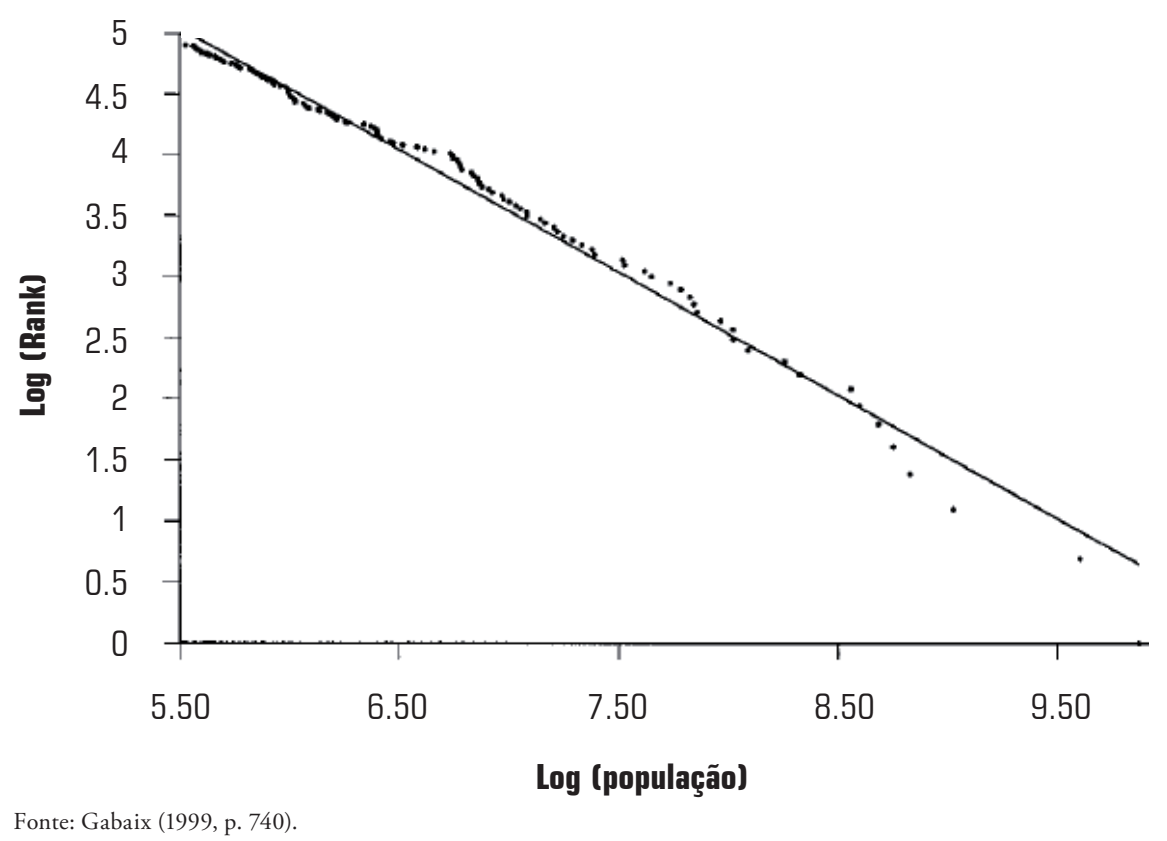

740). Basicamente, nota-se a ocorrência de uma relação negativa entre tamanho de uma cidade (medido via população) e sua posição no ranking de tamanho. Em particular, quando essa relação entre variáveis é inversamente proporcional (coeficiente estimado iguala a unidade), verifica-se a ocorrência da Lei de Zipf.

Ao contrário da distribuição normal, em que elementos distantes da média possuem frequência de ocorrência re- lativamente pequena, uma distribuição de "cauda longa" (nos moldes da distribuição de Zipf e Pareto) equivale a uma distribuição na qual alguns poucos elementos possuem alta frequência, enquanto a vasta maioria desses elementos possui baixa frequência. O Gráfico 4 contém uma representação esquemática da distribuição de Pareto para distintos valores do parâmetro $\zeta$. 


\section{Gráfico 4_Distribuição de Pareto, distintos valores do parâmetro $\zeta$}

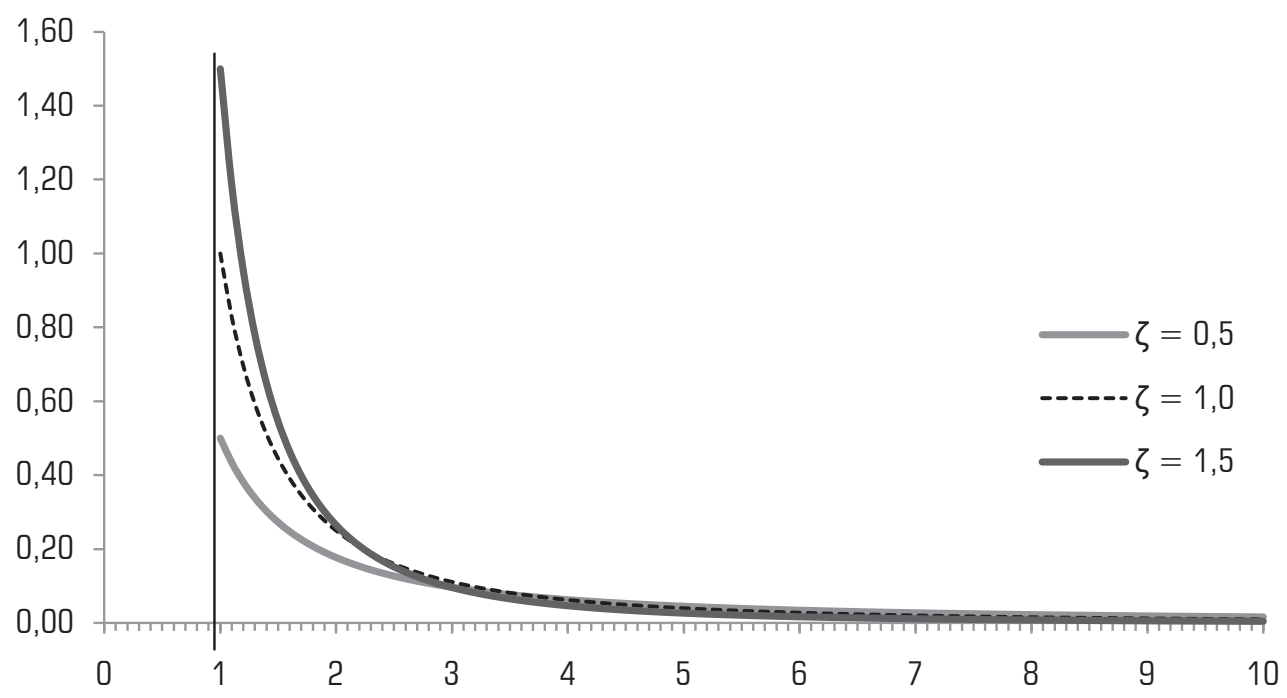

Fonte: Cálculos dos autores.

A partir da inspeção do gráfico acima, pode-se notar que alguns elementos dessa distribuição possuem alta frequência de ocorrência, ao passo que os demais elementos apresentam frequência relativamente baixa. Todas as curvas contidas na figura representam distribuições de Pareto para distintos valores do parâmetro de interesse $\zeta$. Em particular, vale notar que, no caso da distribuição onde $\zeta=1$, tem-se a representação gráfica da Lei de Zipf.

\section{4_ Literatura relacionada ${ }^{13}$}

A presente seção contém uma revisão parcial da literatura relacionada ao tema. Especificamente, esta seção trata de dois subtemas específicos: (i) a importância de investimentos em escala regional; (ii) a evidência empírica disponível relacionada às Leis de Zipf e Pareto, com ênfase em temas urbanos.

Uma tentativa de estabelecer fatos estilizados relacionados ao investimento agregado equivale ao estudo de Leahy
13 Os autores agradecem a um parecerista anônimo por sugerir uma seção nesses moldes. 
14 Para um breve resumo de algumas das principais teorias relacionadas ao investimento agregado elaboradas ao longo do século XX, ver Caballero (2000). e Whited (1995), em que esses autores buscam entender a relação entre investimento e fatores relacionados à incerteza no curto prazo. Para tanto, testam diversas hipóteses relacionadas a teorias de investimento a partir de um painel que cobre uma amostra de 772 firmas ao longo do período 1981-1987. Os resultados obtidos demonstram a existência de uma relação nitidamente negativa entre investimentos e incerteza, um padrão consistente com teorias que ressaltam o caráter irreversível do investimento agregado. ${ }^{14}$

Luporini e Alves (2010) analisam os determinantes do investimento privado no Brasil durante o período 19702005. Além de realizarem uma revisão de alguns dos principais estudos relacionados ao tema, as autoras apresentam evidências empíricas baseadas em dados macroeconômicos, que chamam a atenção para a importância de variáveis como renda, nível de atividade, volume de crédito, taxa de câmbio e uma medi$\mathrm{da}$ de instabilidade política, que tendem a afetar o investimento privado; ao mesmo tempo em que corroboram a importância do efeito acelerador e de irreversibilidades associadas aos investimentos realizados. Em termos gerais, a principal prescrição derivada desses resultados equivale à implementação de políticas voltadas para a manutenção da estabilida- de econômica e credibilidade dos agentes, assim como aumentos na oferta de crédito, dada sua importante contribuiçãao ao investimento agregado.

Com base em dados da Pesquisa Industrial Anual (PIA), Britto (2010) apresenta uma análise exploratória dos determinantes de investimentos industriais no Brasil, entre 1996 e 2006. Especificamente, o autor busca analisar simultaneamente os efeitos de variáveis no nível da firma e nos setores de atuação dessas, tendo como base a estimação de modelos hierárquicos. Entre os resultados obtidos, chama a atenção a natureza fragmentária das decisões individuais de investimento, uma vez que parte das firmas da amostra analisada não declara valores de investimento. Adicionalmente, os resultados atestam a importância do setor de atuação das firmas para as decisóes de investimento, assim como confirmam o princípio acelerador, em moldes semelhantes a Luporini e Alves (2010).

Relacionado ao contexto regional brasileiro, há o trabalho de Silveira (2005), que estuda os determinantes de curto prazo dos investimentos estaduais no Brasil, no período 1996-2000. Em particular, essa autora tenta mensurar empiricamente os principais determinantes do investimento agregado nos Estados brasileiros a partir do uso de técnicas econométricas 
de dados em painel. Os resultados obtidos apontam para a importância de variáveis relacionadas à instabilidade econômica, aos preços dos fatores de produção e ao "efeito-deslocamento" (crowding-out) de investimentos públicos sobre investimentos privados.

Pessoti e Pessoti (2008) elaboram uma análise das políticas de atração de investimentos industriais para o Estado da Bahia, no período 2000-2004, com ênfase na região do Recôncavo baiano. Basicamente, esses autores realizam uma análise de padrôes de concentração setorial e espacial dos investimentos ocorridos nesse Estado, durante o período considerado. Os resultados obtidos demonstram a ocorrência de nítido padrão de concentraçâo desses investimentos, não havendo tendência de modificação da dinâmica econômica inerente à região do Recôncavo, outrora uma das de maior destaque no Estado em análise.

Voltado para o contexto espírito-santense, o trabalho de Iglesias (2010) analisa a importância econômica de grandes projetos de investimento para o Estado do Espírito Santo, entre 2000-2009, assim como os principais impactos esperados desses. Uma das principais conclusôes obtidas pelo autor equivale ao fato de que a maioria das atividades econômicas associadas a esses projetos teve em média impacto positivo em termos de participação na estrutura do emprego estadual, com esse impacto sendo, em geral, superior em comparação ao resto do país. Adicionalmente, o autor atenta para a crescente importância do setor petrolífero no Estado, que, por requerer maior grau de variedade de insumos e serviços, pode vir a gerar desenvolvimento de capacidade gerencial e produtiva em diversos setores locais. ${ }^{15}$

O trabalho de Caçador e Grassi (2009) também equivale a uma pesquisa relacionada ao Espírito Santo. Basicamente, esse trabalho se propóe a responder à seguinte pergunta: por que o Estado, apesar de apresentar indicadores econômicos (PIB per capita, exportaçóes, $\mathrm{IDH}$, taxa de pobreza) que o colocam acima da média nacional, ainda apresenta baixo desempenho em termos de indicadores relacionados à geração de conhecimento? A análise desses autores sugere que o ES ainda investe parcela relativamente pequena de recursos na área de Ciência e Tecnologia (C\&T), o que acaba reforçando um processo de "diversificação concentradora”, em que, apesar de ter havido ampliação do leque de atividades desenvolvidas localmente, ainda há nítido padrão de concentração setorial (produção de commodities). ${ }^{16}$
15 Para análises relacionadas ao setor de petróleo no Espírito Santo, ver Oliveira (2010) e Pires (2010).

16 Para uma análise da evolução da economia do Espírito Santo, no período 1980-2000, com ênfase no contexto político vigente, ver Oliveira, Villaschi Filho e Felipe (2010). Sobre a importância empírica de preços de commodities para a economia estadual, ver Magalhães (2011). 
Um estudo com objetivos semelhantes aos de Pessoti e Pessoti (2008) e aplicado ao Estado do Espírito Santo equivale ao trabalho de Magalhães e Toscano (2011a), no qual os autores buscam mensurar o grau de concentração dos investimentos previstos para o Espírito Santo, no período 2008-2013, a partir da construção de índices de concentração espacial e especialização setorial para as microrregióes administrativas do Estado. Os resultados obtidos demonstram que a ampla maioria dos projetos de investimento analisados encontra-se concentrada na Região Metropolitana (equivalente aos municípios de Vitória, Vila Velha, Ser-

\footnotetext{
17 A maioria das aplicaçóes das Leis de Zipf e Pareto está relacionada ao estudo de cidades e firmas, basicamente. Para explicaçóes sobre essas leis, ver Adamic (2002) e Gabaix (2008). Uma resenha relacionada à aplicação dessas leis em Economia Urbana equivale a Gabaix e Ioannides (2004). Exemplos de estudos empíricos voltados para o contexto internacional equivalem a Gabaix (1999), Ioannides e Overman (2003), Nitsch (2005) e Soo (2005). Por outro lado, exemplos de aplicaçóes relacionadas ao contexto de teorias de comércio internacional
}

equivalem aos estudos de Easterly e Reshef (2009) e di Giovanni, Levchenko e Rancière (2010).

${ }_{18}$ De acordo com a Lei de Gibrat, o fenômeno de crescimento de cidades tende a seguir processos de crescimento similares, com esses processos exibindo um mesmo valor em termos de média e variância, por exemplo (Gabaix, 1999, p. 741).

${ }_{19}$ Nesse sentido, seria interessante a realização de um estudo nesses moldes voltado para a questão da dinâmica de investimentos regionais, por exemplo. Mais detalhes adiante. ra, Cariacica, Guarapari, Viana e Fundão), ao mesmo tempo em que ocorre alto grau de especialização setorial nas demais microrregióes. Conforme dito acima, esses resultados chamam a atençáo para a ocorrência de fortes padróes de concentração na economia local, em última instância.

Adicionalmente, vale ressaltar que, nos últimos anos, ocorreram esforços relacionados a testar a adequação empírica das Leis de Zipf e Pareto, especialmente no contexto de cidades, em consonância com a literatura internacional sobre o tema. ${ }^{17}$ Por exemplo, Gabaix (1999) equivale a um estudo nesses moldes, em que o autor elabora um modelo que busca explicar a ocorrência da Lei de Zipf no contexto de cidades de diferentes países, durante distintos períodos históricos. Os resultados obtidos demonstram que explicaçôes dessa lei podem ser reduzidas a explicaçóes baseadas em uma lei mais simples, a de Gibrat, ${ }^{18}$ ao mesmo tempo em que ressaltam os motivos pelos quais amostras que contêm cidades menores tendem, em geral, a rejeitar a Lei de $\mathrm{Zi}$ pf, uma vez que essas cidades apresentam maior variância do que cidades maiores. ${ }^{19}$

Ruiz (2005) realiza um estudo comparando a estrutura urbana do Brasil e dos Estados Unidos. Segundo o autor, a literatura relacionada à área de Economia Urbana tende a caracterizar países 
em desenvolvimento como aqueles que possuem estrutura urbana concentrada e desigual, ao mesmo tempo em que países desenvolvidos apresentam redes urbanas mais equilibradas. A partir da construção de indicadores de concentração urbana e estimativas de formas funcionais referentes às Leis de Zipf e Pareto, o autor conclui que a distribuição de tamanho de cidades, no caso brasileiro, pode ser caracterizada como constituída por grandes centros urbanos, ao contrário do caso norte-americano, onde cidades médias possuem maior importância relativa. Em termos de políticas urbanas, o autor recomenda maior investimento em regióes não metropolitanas, já que, no Brasil, cidades médias não tiveram as mesmas oportunidades de crescimento comparativamente às grandes cidades. ${ }^{20}$

Miranda e Badia (2006) testam a ocorrência da Lei de Zipf para o contexto dos municípios de Minas Gerais, no longo período compreendido entre 1920 e 2000. Basicamente, os autores querem checar a eventual ocorrência de padróes concentradores durante o processo de evolução das cidades mineiras, no período analisado. Os resultados obtidos pelos autores confirmam a ocorrência desses padróes, com ênfase no crescimento da capital do Estado, Belo Horizonte, ao longo do século XX.
Por sua vez, Magalhães e Toscano (2011b) também buscam verificar a validade empírica das Leis de Pareto e Zipf para os municípios do Espírito Santo, entre 1999 e 2007. De acordo com os resultados reportados pelos autores, o tamanho dos municípios espírito-santenses pode ser caracterizado a partir de uma distribuição de cauda longa. Ainda assim, a Lei de Zipf parece não ter validade empírica no caso desse conjunto de localidades, uma vez que os coeficientes estimados apontam para valores nitidamente distintos daquele preconizado por essa lei. Adicionalmente, constatam que quatro municípios da Região Metropolitana (Vitória, Vila Velha, Cariacica e Serra) respondem por uma parcela superior a $40 \%$ da população total do Estado, resultado que reforça um padrão de polarização populacional nessas localidades.

Com base nas contribuiçóes supracitadas, o presente trabalho buscará analisar empiricamente a distribuição dos projetos de investimento planejados para o Estado, assim como testar a ocorrência da Lei de Zipf nesse caso, conforme descrito a seguir.

\section{5_Base de dados}

As variáveis utilizadas neste trabalho equivalem a projetos de investimento previs-

\footnotetext{
20 Sobre a importância das cidades médias brasileiras para os processos de crescimento populacional e redistribuição da populaçáo urbana, no período 1970-1991, ver Andrade e Serra (1998).
} 


\footnotetext{
21 Entre as instituiçôes conveniadas, podem-se citar, a título de exemplo, a Secretaria de Meio Ambiente e Recursos Hídricos (SEAMA), o Banco de Desenvolvimento do Espírito Santo S/A (BANDES), as Secretarias Estaduais de Planejamento (SEP), Saúde (SESA), Educação (SEDU) e Desenvolvimento (SEDES), entre outras.

22 Para mais detalhes relacionados à metodologia da pesquisa supracitada, ver Taveira et al. (2010, p. 62-64).

${ }^{23}$ Especificamente, o valor de cada projeto individual contido no banco de dados do IJSN é dividido pelo IGP-M, com a base de comparação escolhida para esse índice correspondendo à média do ano de 2009.
}

tos para o Espírito Santo, entre 2009-2014, com sua fonte primária equivalendo ao documento "Investimentos Previstos no Espirito Santo: 2009-2014" (Taveira et al., 2010). Em termos gerais, esse documento corresponde a um levantamento sistemático de intençóes de investimento relacionadas ao Estado, em um período de cinco anos. Os projetos de investimento contemplados podem ser tanto de origem pública quanto privada, equivalendo a investimentos correspondentes a valores maiores ou iguais a $R \$ 1$ milhão (um milhão de reais).

As fontes primárias dos dados utilizados nessa pesquisa equivalem a levantamentos feitos diretamente pelo Instituto Jones dos Santos Neves (IJSN), órgão de pesquisa do Estado do Espírito Santo. Os projetos reportados nessa pesquisa são obtidos com base em anúncios de investimentos divulgados pelos principais meios de comunicação em âmbitos nacional e estadual. Adicionalmente, alguns dados são obtidos valendo-se de convênios entre o IJSN e instituiçóes públicas. ${ }^{21}$ Em um segundo momento, é feita uma averiguação dessas informaçóes, com a equipe técnica do IJSN, buscando confirmar os anúncios iniciais, assim como evitar problemas de dupla contagem. ${ }^{22}$

Para facilitar a comparação entre projetos de investimento anunciados em distintos períodos de tempo, os dados originais são deflacionados baseando-se no Índice Geral de Preços do Mercado (IGP$\mathrm{M})$, calculado pela Fundação Getúlio Vargas (FGV). ${ }^{23}$ Adicionalmente, os valores dos investimentos previstos podem ser divididos de acordo com o município ao qual estão destinados, assim como a microrregião administrativa que engloba um dado conjunto de municípios.

Duas ressalvas relacionadas à pesquisa supracitada devem ser feitas no presente contexto. Primeiro, a pesquisa contempla apenas investimentos previstos para o Espírito Santo, ou seja, ela equivale basicamente a uma pesquisa de investimentos planejados para o Estado, e não investimentos efetivos. Segundo, em razão de a pesquisa ser baseada em investimentos anunciados, há a possibilidade de ocorrência de alguns vieses nos resultados obtidos, decorrência direta da metodologia empregada. Ainda assim, os resultados apresentados podem ser úteis no sentido de apontar relevantes direçóes de movimento dos fluxos de capitais que ingressam ou venham a ingressar no Estado, assim como ressaltar possíveis potenciais de crescimento futuro de áreas específicas.

Por outro lado, vale a ressalva adicional de que, apesar de tal pesquisa ser realizada desde o ano de 2000, alguns dos aspectos metodológicos supracitados foram 
introduzidos apenas a partir de 2009, o que impossibilita uma comparação direta de seus resultados com números anteriores do documento, justificando a escolha do atual período de análise (2009-2014).

\section{6_Resultados}

\section{1_Análise descritiva}

A Tabela 5 apresenta resultados relacionados aos projetos de investimento previstos para o Estado do Espírito Santo, no período 2009-2014, divulgados de acordo com o setor e a área aos quais esses investimentos pertencem. O montante total de investimentos previstos para o Espírito Santo, com valores superiores a R \$ 1 milhão, no período analisado, foi de $\mathrm{R} \$$ 62,2 bilhões, sendo esses divididos em 972 projetos, com valor médio estimado em R \$ 63,9 milhóes por projeto. Tal montante encontra-se distribuído entre os principais setores econômicos do Estado, conforme ilustrado na tabela abaixo.

A segunda coluna da tabela contém o número de projetos de investimento referente a cada setor, enquanto a terceira coluna contém a respectiva participação desses projetos no total da amostra. Por sua vez, a quarta coluna apresenta o valor total desses projetos, com a quinta coluna mostrando a participação desses valores no total. A sexta coluna da tabela apresenta o valor médio de cada projeto, obtido a partir da divisão dos valores contidos na quarta coluna pelos valores contidos na segunda.

De acordo com os valores expostos na Tabela 5, pode-se notar que, em termos de número, a ampla maioria dos projetos considerados $(33,7 \%)$ concentra-se na área de Infraestrutura, composta dos setores de Energia (7,3\%), Transporte (18,6\%) e Terminal Portuário/Aeroportuário e Armazenagem (7,8\%). Em seguida, vêm as áreas de Indústria e Comércio/Serviços e Lazer, com participação de 10,8\% cada uma. Os demais projetos $(42,6 \%)$ pertencem à área intitulada Outros Serviços, que compreende os setores de Saneamento/Urbanismo (15,2\%), Educação (17,7\%), Meio Ambiente (0,8\%), Saúde (7,7\%) e Segurança Pública $(1,1 \%)$.

Em relação aos valores dos projetos de investimento considerados na amostra, nota-se que mais da metade pertence à área de Infraestrutura (52,3\%), estando concentrados principalmente no setor de Energia (32,2\%). A área industrial vem em seguida, com valores equivalentes a pouco menos de um terço $(32,7 \%)$ do total de projetos de investimento. Por sua vez, as áreas Comércio/Serviço e Lazer e Outros Serviços apresentam menor participação, em torno de 7\%, cada uma. 
Tabela 5_Investimentos, segundo setores, por número de projetos e total dos investimentos, 2009-2014 (R\$ 1 milhão)

\begin{tabular}{|c|c|c|c|c|c|}
\hline Setores & $\begin{array}{c}\text { Número } \\
\text { de projetos (1) }\end{array}$ & Part. \% & $\begin{array}{l}\text { Valor total dos } \\
\text { investimentos (2) }\end{array}$ & Part. \% & $\begin{array}{l}\text { Valor médio } \\
\text { Projeto (2)/(1) }\end{array}$ \\
\hline Infraestrutura & 328 & 33,7 & 32.508 & 52,3 & 99,1 \\
\hline Energia & 71 & 7,3 & $20.003,4$ & 32,2 & 281,7 \\
\hline Transporte & 181 & 18,6 & $6.771,3$ & 10,9 & 37,4 \\
\hline $\begin{array}{l}\text { Terminal Portuário/ } \\
\text { Aeroportuário e Armazenagem }\end{array}$ & 76 & 7,8 & $5.733,1$ & 9,2 & 75,4 \\
\hline Indústria & 105 & 10,8 & $20.322,7$ & 32,7 & 193,5 \\
\hline Comércio/Serviço e Lazer & 105 & 10,8 & $4.203,4$ & 6,8 & 40,0 \\
\hline Outros Serviços & 414 & 42,6 & 4.421 & 7,1 & 10,7 \\
\hline Saneamento/Urbanismo & 148 & 15,2 & $1.960,8$ & 3,2 & 13,2 \\
\hline Educação & 172 & 17,7 & $1.113,5$ & 1,8 & 6,5 \\
\hline Meio Ambiente & 8 & 0,8 & 704,0 & 1,1 & 88,0 \\
\hline Saúde & 75 & 7,7 & 470,6 & 0,8 & 6,3 \\
\hline Segurança Pública & 11 & 1,1 & 172,3 & 0,3 & 15,7 \\
\hline Agroindústria & 20 & 2,1 & 696,6 & 1,1 & 34,8 \\
\hline Total & 972 & 100 & $62.151,8$ & 100,0 & 63,9 \\
\hline
\end{tabular}

Fonte: Cálculos dos autores.

Em relação aos valores médios dos projetos de investimento considerados, nota-se que o maior valor registrado corresponde à área industrial, com valor médio estimado em torno de $\mathrm{R} \$ 193,5 \mathrm{mi}-$ lhôes. A área de Infraestrutura aparece em seguida, com valor de $\mathrm{R} \$ 99$ milhóes, e o setor de Energia apresenta valor médio por projeto estimado de cerca de $\mathrm{R} \$ 282$ milhóes. À primeira vista, esses resultados apontam para a ocorrência de um padrão heterogêneo dos valores de projetos de investimento analisados, de acordo com a área e/ou setor considerado.

O Gráfico 5 reforça alguns dos pontos mencionados acima. Nele são apresen- 
Gráfico 5_Diagramas "boxplot" dos valores dos investimentos previstos por setor - Espírito Santo, 2009-2014

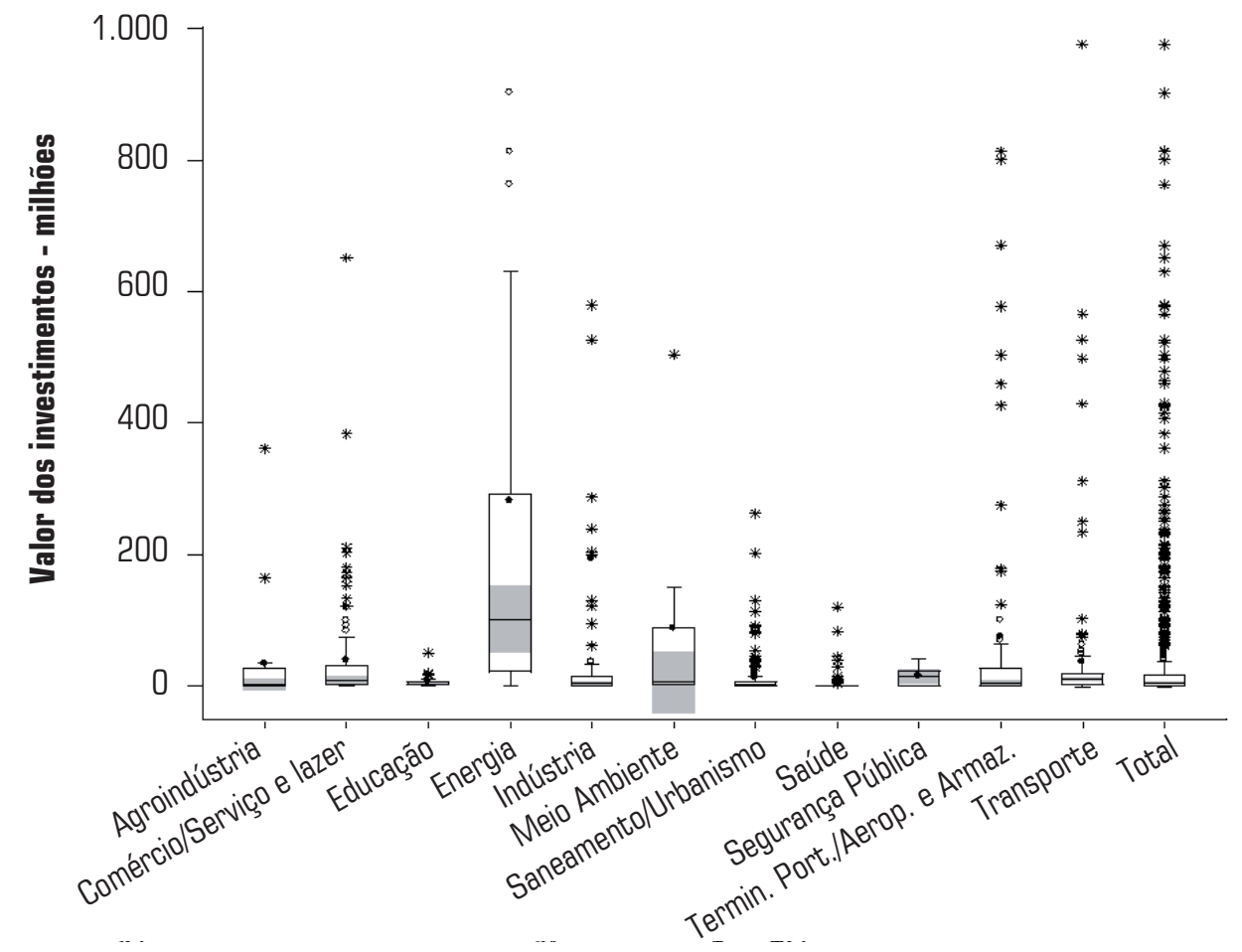

Fonte: Cálculos dos autores.

tados diagramas boxplot relacionados aos investimentos previstos para o Estado. No que diz respeito a esses gráficos, as "caixas" apresentadas representam a distribuição dos dados, considerando-se o primeiro e o terceiro quartis da distribuição, com o "fundo" da caixa equivalendo aos dados superiores a 25\% da distribuição (primei- ro quartil), ao passo que o "topo" da caixa equivale aos dados superiores a $75 \%$ da distribuição (terceiro quartil). Por sua vez, a linha reta interior à caixa equivale aos dados localizados exatamente na metade, sendo superiores a $50 \%$ da distribuição (segundo quartil ou mediana). Pontos negros equivalem à média da dis- 
tribuição, enquanto pontos brancos e asteriscos equivalem a "valores aberrantes" (outliers). Finalmente, áreas sombreadas equivalem a intervalos de confiança referentes à mediana da distribuição.

Em termos de distribuição setorial dos investimentos, nota-se a ocorrência de um padrão nitidamente assimétrico entre os projetos considerados para o período 2009-2014. Especificamente, parece haver alto grau de assimetria entre os projetos considerados, assim como a presença de valores aberrantes (outliers) na maioria dos casos. De acordo com os resultados reportados, a maior parte desses projetos encontra-se concentrada nas áreas de Induistria e Infraestrutura, tradicionalmente responsáveis pela maioria dos valores analisados. A única exceção a esses padróes de assimetria equivale ao setor de Segurança Pública, que apresenta distribuição mais centrada em torno da média quando da comparação com os demais setores.

O caráter assimétrico da distribuição de projetos de investimento previstos para o Estado fica ressaltado a partir do Gráfico 6, que contém histogramas relacionados aos projetos de investimento previstos para o Estado, de acordo com diferentes estratos da distribuição considerada, construídos com base em distintos tamanhos amostrais. No eixo hori- zontal de cada gráfico, estão registrados os números de projetos, ao passo que no eixo vertical estão as respectivas frequências relativas.

De maneira geral, os padróes gráficos reportados demonstram que há ampla concentração de projetos em termos de montantes; ou seja, um número relativamente pequeno de projetos responde pelos maiores valores reportados na amostra considerada, com a ampla maioria dos projetos respondendo por parcelas consideravelmente menores. Esse resultado está de acordo com o fenômeno de "cauda longa", comum em diversos contextos na área de economia, conforme citado acima.

Especificamente, é interessante notar que o padrão de cauda longa dos projetos de investimento analisados parece variar de acordo com o tamanho do estrato considerado. Em particular, embora o aspecto gráfico da distribuição de projetos de investimento seja mantido em termos qualitativos, os formatos específicos das distribuiçôes em análise parecem mudar à medida que varia o número de projetos contidos na amostra.

A Tabela 6 apresenta os valores dos projetos contidos em estratos específicos, bem como sua respectiva participação no total da amostra. 
Gráfico 6_Histograma dos 100 maiores projetos de investimento destinados ao Estado do Espírito Santo, 2009-2014
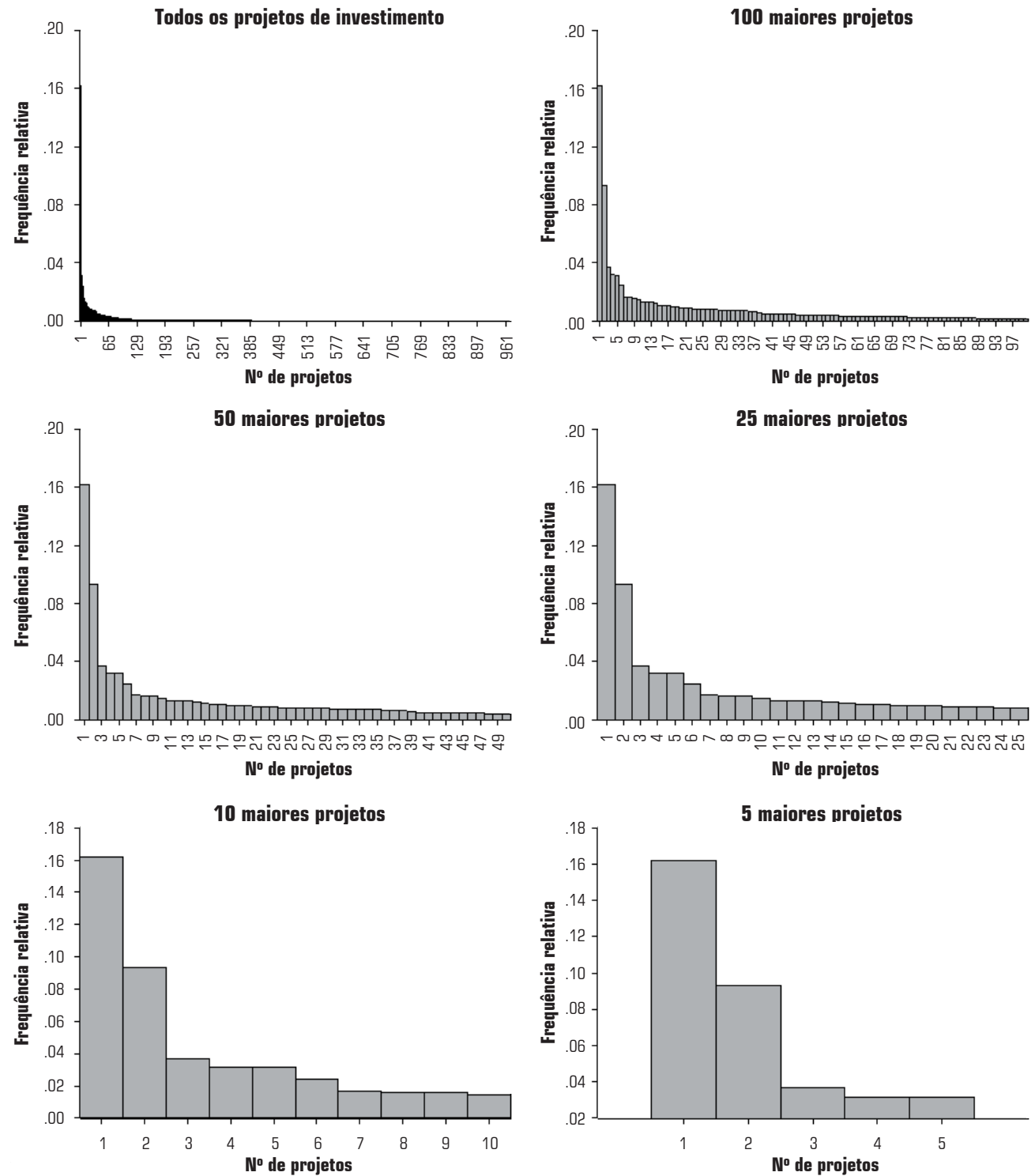

Fonte: Cálculos dos autores. 
Tabela 6_Participação de estratos específicos no total da amostra de projetos de investimento

\begin{tabular}{|c|c|c|}
\hline Estratos & Valor R\$ (milhões) & Part. \% \\
\hline 5 maiores & 22.129 & $36 \%$ \\
\hline 10 maiores & 27.558 & $44 \%$ \\
\hline 20 maiores & 34.424 & $55 \%$ \\
\hline 25 maiores & 37.008 & $60 \%$ \\
\hline 50 maiores & 45.952 & $74 \%$ \\
\hline 100 maiores & 53.561 & $86 \%$ \\
\hline Total & 62.152 & $100 \%$ \\
\hline
\end{tabular}

Fonte: Cálculos dos autores.

Os resultados expostos na tabela demonstram que a participação dos distintos estratos varia diretamente com o tamanho desses estratos. Em particular, é interessante notar que o estrato equivalente aos 20 maiores projetos corresponde a mais da metade dos valores do total de projetos (55\%), com os 50 maiores projetos respondendo por quase três quartos da amostra como um todo $(74 \%)$. Por outro lado, observa-se que os 100 maiores projetos de investimento respondem por $86 \%$ da amostra. Esses resultados são interessantes por demons- trarem a possibilidade de inferências representativas acerca do total de projetos de investimento previstos para o Estado a partir de estratos de tamanho relativamente pequeno (como os 50 ou 100 maiores projetos, por exemplo).

A Tabela 7, por sua vez, considera as estatísticas descritivas dos projetos de investimento previstos para distintos estratos da amostra sob análise, incluindo a amostra como um todo. No caso, a intenção básica equivale a ressaltar as diferenças entre esses estratos a partir das diferenças reportadas para as estatísticas supracitadas. 
Tabela 7_Estatísticas descritivas de investimentos previstos no Estado (milhões R\$) - estratos selecionados da amostra total

\begin{tabular}{|c|c|c|c|c|c|c|}
\hline Estratos & Média & Mediana & Máximo & Mínimo & Desvio padrão & $N$ \\
\hline 5 maiores & 4425,88 & 2306,51 & 10078,63 & 1963,90 & 3551,00 & 5 \\
\hline 10 maiores & 2755,79 & 1740,33 & 10078,63 & 902,65 & 2954,68 & 10 \\
\hline 20 maiores & 1721,19 & 857,95 & 10078,63 & 566,15 & 2294,99 & 20 \\
\hline 25 maiores & 1480,30 & 800,58 & 10078,63 & 503,93 & 2100,36 & 25 \\
\hline 50 maiores & 919,04 & 501,34 & 10078,63 & 234,74 & 1576,73 & 50 \\
\hline 100 maiores & 535,61 & 234,50 & 10078,63 & 83,90 & 1174,78 & 100 \\
\hline Total & 63,94 & 5,71 & 10078,63 & 0,06 & 407,94 & 972 \\
\hline
\end{tabular}

Fonte: Cálculos dos autores.

Os resultados contidos na tabela apontam para a ocorrência de nítidas mudanças nos valores das estatísticas descritivas dos projetos de investimento de acordo com o estrato da amostra considerado. Em particular, nota-se que esses valores tendem a diminuir à medida que maiores parcelas da amostra são consideradas. Aqui, chama a atenção o fato de que os valores referentes às estatísticas descritivas para a amostra como um todo são muito destoantes dos valores referentes a estratos específicos. Esse resultado, além de reforçar o caráter assimétrico da distribuição de investimentos previstos para o Estado, demonstra que, à primeira vista, inferências baseadas na amostra total podem vir a náo representar a realidade inerente à maior parte dos projetos de investimento analisados.

\section{Com o objetivo de verificar a} ocorrência de padrões assimétricos na amostra, a Tabela 8 apresenta resultados relacionados a estratos específicos, tanto em termos de média dos valores dos projetos quanto de medidas de simetria, curtose e do teste de normalidade de JarqueBera (Jarque; Bera, 1987). ${ }^{24}$

Os resultados expostos confirmam a ocorrência de nítidas diferenças entre os
${ }^{24}$ Vale a ressalva de que, dado o tamanho reduzido de algumas subamostras, esses resultados possuem caráter meramente ilustrativo. 
Tabela 8_Características estatísticas da distribuição de projetos de investimento previstos para o Espírito Santo, amostra total e estratos específicos (milhões de $\mathbf{R} \$$ )

\begin{tabular}{|c|c|c|c|c|c|}
\hline Estratos & Média & Simetria & Curtose & Jarque-Bera & Probabilidade \\
\hline 5 maiores & 4425,88 & 0,90 & 2,20 & 1 & 0,67 \\
\hline 10 maiores & 2755,79 & 1,80 & 4,87 & 7 & 0,03 \\
\hline 20 maiores & 1721,19 & 2,86 & 10,33 & 72 & 0,00 \\
\hline 25 maiores & 1480,30 & 3,25 & 12,99 & 148 & 0,00 \\
\hline 50 maiores & 919,04 & 4,66 & 25,67 & 1.252 & 0,00 \\
\hline 100 maiores & 535,61 & 6,42 & 48,68 & 9.381 & 0,00 \\
\hline Total & 63,94 & 18,65 & 417,25 & 7.006 .355 & $\mathbf{0 , 0 0}$ \\
\hline
\end{tabular}

Fonte: Cálculos dos autores.

estratos analisados. Conforme dito acima, nota-se que a média dos projetos tende a aumentar à medida que menores estratos são considerados. Por exemplo, enquanto a média de valor dos projetos da amostra total equivale a $\mathrm{R} \$ 63,94$ milhôes, esse valor aumenta cerca de oito vezes quando considerado o estrato que contém os 100 maiores projetos ( $\mathrm{R} \$ 535,61$ milhóes). No caso da comparação entre o estrato que abriga os cinco maiores projetos e o total da amostra, a diferença de valores chega a quase 70 vezes.

Adicionalmente, as estatísticas referentes à simetria e à curtose da distri- buição de projetos de investimento também apontam para nítidas diferenças entre a amostra e os estratos específicos. Em termos de simetria, tanto a amostra total quanto os estratos específicos considerados apresentam padrão de assimetria à direita, consistente com distribuiçóes de cauda longa. Por outro lado, a ampla maioria dos estratos considerados apresenta excesso de curtose, o que permite caracterizar as distribuições de projetos de investimento daí derivadas como leptocúrticas, um resultado também em consonância com distribuições de cauda longa. 
A exceção a esses padróes empíricos fica por conta do estrato que encerra os cinco maiores projetos de investimento, cuja distribuição apresenta estatísticas que permitem caracterizá-la como relativamente mais simétrica que os demais estratos, assim como platicúrtica e aproximadamente normal, já que não é possível rejeitar a hipótese nula do teste JarqueBera, neste caso específico. Conforme citado, vale a ressalva de que este último resultado pode ser uma decorrência do reduzido tamanho da amostra em questão.

Uma forma alternativa de mensurar padrôes de concentração da distribuição de projetos de investimento do Estado equivale ao cálculo de índices de primazia. Basicamente, esses índices correspondem a medidas de tamanho relativo dos projetos de investimento, fornecendo o tamanho do maior projeto em relação a um dado número de projetos. Formalmente, esse índice pode ser representado a partir da seguinte fórmula:

$$
P_{j}=N_{1} / N_{1}+N_{2}+. .+N_{j}
$$

onde o termo $P_{j}$ representa a primazia de “j-ésima” ordem, enquanto $N_{i}(\mathrm{i}=1,2, \ldots, \mathrm{j})$ representa o tamanho do "i-ésimo" projeto.

$\mathrm{Na}$ presente análise, optou-se pela construçáo de índices alternativos de primazia, referentes aos 5, 10, 25, 50 e 100 maiores projetos de investimento do Estado, assim como ao total da amostra. A Tabela 9 expóe resultados relacionados a esse indicador.

\section{Tabela 9 Indicadores de primazia dos investimentos previstos - Espírito Santo, 2009-2014}

\begin{tabular}{|c|c|}
\hline Estratos & ES \\
\hline Primazia 5 & 0,455 \\
\hline Primazia 10 & 0,366 \\
\hline Primazia 25 & 0,272 \\
\hline Primazia 50 & 0,219 \\
\hline Primazia 100 & 0,188 \\
\hline Primazia Total & 0,162 \\
\hline
\end{tabular}

Fonte: Cálculos dos autores.

Os resultados referentes aos indicadores construídos demonstram que os valores considerados variam de acordo com o tamanho da amostra analisada. Assim, pode-se notar que, enquanto esse indicador assume valor de 0,46 em relação aos cinco maiores projetos de investimento, os valores obtidos apresentam tendência decrescente à medida que novos projetos são incorporados na amostra. Por exemplo, no caso dos 25 maiores projetos, o indicador assume valor de 0,27 (redução de $40 \%$ em relação aos cinco 
Gráfico 7_Valor do maior investimento/valor do menor investimento - Estratos selecionados

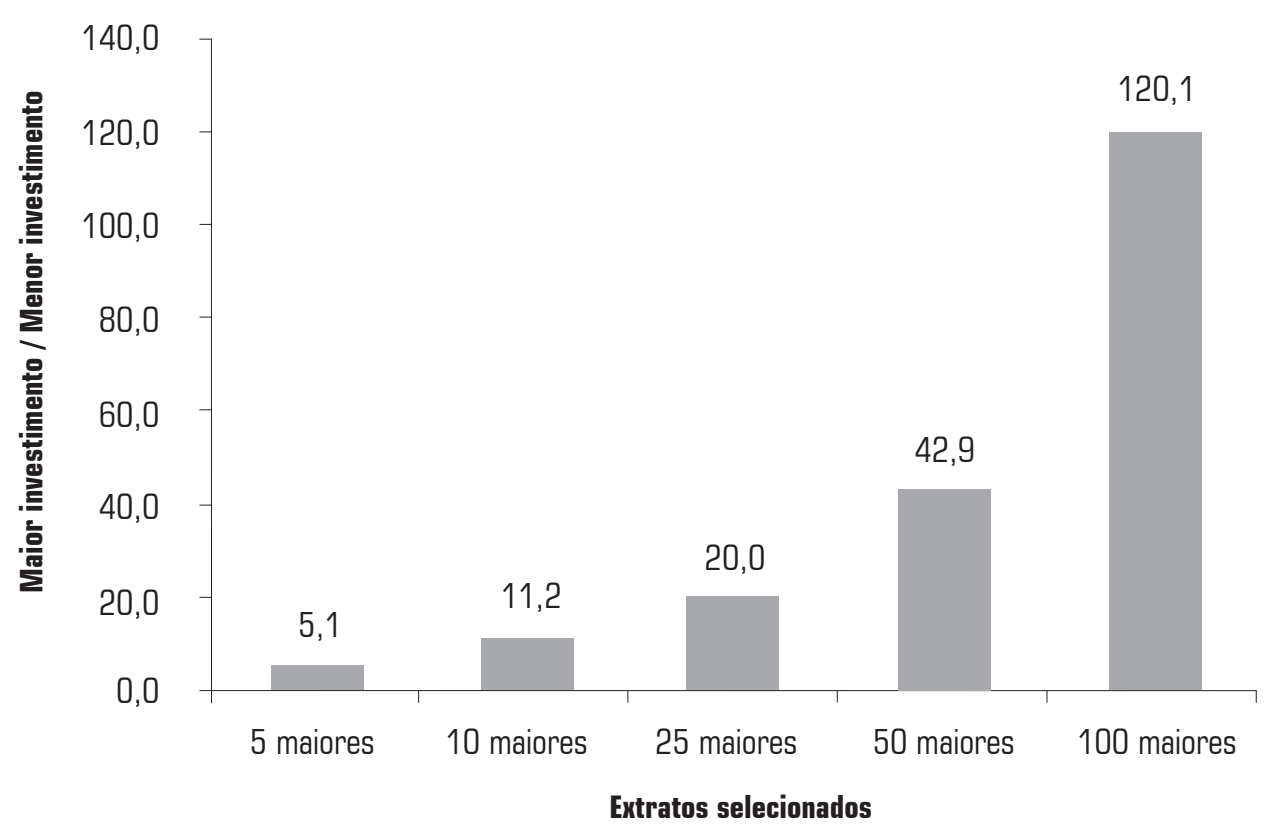

Fonte: Cálculos dos autores.

maiores projetos), chegando a um valor de 0,19 no que concerne aos 100 maiores projetos da amostra (redução de 60\%).

Esses resultados confirmam o caráter assimétrico da distribuição de projetos de investimento previstos para o Estado, uma vez que demonstram que os indicadores de primazia assumem valores nitidamente superiores quando se trata de estratos de tamanho reduzido que contêm os maiores projetos, com esses valores decrescendo à medida que o tamanho dessas amostras aumenta. Em termos gerais, os resultados obtidos demonstram que inferências baseadas unicamente nas propriedades estatísticas da amostra como um todo podem vir a ser enganosas, dadas as diferenças verificadas entre os estratos analisados.

O Gráfico 7 considera a evolução temporal da razão entre o maior e o menor projeto de investimento em termos de valores.

De acordo com o gráfico, nota-se que, quando são considerados os cinco 
maiores projetos de investimento previstos para o Estado, a razão entre o maior e o menor valor equivale a cinco vezes. $\mathrm{Ou}$ seja, no caso desse estrato amostral específico, o maior projeto de investimento possui valor cerca de cinco vezes superior ao menor projeto. Por outro lado, ao se considerar os dez maiores projetos, essa razão pula para 11 vezes, chegando a 20 vezes, quando se trata dos 25 maiores projetos. Já para os 100 maiores projetos, essa proporção chega a 120 vezes. Um fato interessante a ser observado equivale à proporcionalidade notada entre as razôes estimadas e os tamanhos dos estratos considerados, com as razóes crescendo quase na mesma proporção que as amostras.

Dado esse padrão de proporcionalidade, seria interessante nesse contexto verificar a adequação empírica das Leis de Pareto e Zipf à distribuição dos projetos de investimento previstos para o Espírito Santo, de acordo com os diferentes estratos considerados. Esse é o objetivo da próxima subseção do trabalho.

\section{2_Resultados econométricos}

Nesta subseção do trabalho, são expostos resultados de estimaçôes referentes a especificações econométricas das Leis de Pareto e Zipf. O objetivo básico equivale à estimação de especificaçóes economé- tricas relacionando projetos de investimento com suas respectivas posiçóes em um ranking decrescente de valores desses projetos como forma de se averiguar a ocorrência de distribuiçóes de cauda longa nos moldes supracitados.

Uma maneira de se confirmar a validade empírica da Lei de Zipf para distintos estratos da amostra equivale à estimação de especificações da seguinte forma:

$$
\ln N\left(n_{i}\right)=\ln A-\zeta \ln (n)_{i}+\varepsilon_{i}
$$

$\mathrm{Na}$ especificação acima, o termo $N(n)$ equivale à posição no ranking de cada projeto de investimento previsto para o Estado, $\operatorname{com} n_{i}$ equivalendo a seu respectivo valor. Por sua vez, o termo $A$ equivale a uma constante a ser estimada, enquanto $\varepsilon_{i}$ equivale a um termo aleatório de erro, independente e identicamente distribuído (i.i.d.). ${ }^{25}$ Estimativas do parâmetro de interesse $(\zeta)$ podem ser obtidas com base no Método de Mínimos Quadrados Ordinários (MMQO), sendo prática comum na literatura especializada sobre o tema (Gabaix; Ioannides, 2004).

Os resultados dessas especificações estão contidos na Tabela 10, que expóe coeficientes estimados referentes aos principais parâmetros de interesse da análise presente, assim como o coefi-
25 As especificaçóes estimadas e a análise econométrica subsequente foram inspiradas nas análises contidas em Gabaix (1999), Ruiz (2005), Soo (2005) e Miranda e Badia (2006). 
${ }^{26}$ Em razáo da possibilidade de ocorrência de problemas de heterocedasticidade, os erros-padrão das estimativas reportadas acima foram calculados tendo como base o Método de White (White, 1980). Vale a ressalva de que, dado o tamanho reduzido de algumas subamostras consideradas, os valores estimados para os coeficientes devem ser vistos com cautela, tendo caráter meramente ilustrativo.

Tabela 10_Coeficientes estimados para a equação (6) - Espírito Santo - 2009 a 2014

\begin{tabular}{|c|c|c|c|}
\hline Estratos & $\zeta$ & $\mathbf{R}^{2}$ ajustado & $N$ \\
\hline 5 maiores & $\begin{array}{c}-0,826^{* * *} \\
(0,1256)\end{array}$ & 0,935 & 5 \\
\hline 10 maiores & $\begin{array}{c}-0,890^{* * *} \\
(0,0448)\end{array}$ & 0,963 & 10 \\
\hline 25 maiores & $\begin{array}{c}-1,071^{* * *} \\
(0,0552)\end{array}$ & 0,966 & 25 \\
\hline 50 maiores & $\begin{array}{c}-1,139^{* * *} \\
(0,0449)\end{array}$ & 0,972 & 50 \\
\hline 100 maiores & $\begin{array}{c}-1,002^{* * *} \\
(0,0218)\end{array}$ & 0,971 & 100 \\
\hline Todos & $\begin{array}{c}-0,574^{* * *} \\
(0,0102)\end{array}$ & 0,958 & 972 \\
\hline
\end{tabular}

Fonte: Cálculos dos autores.

Notas:

(a) Erros-padráo das estimativas reportadas entre parênteses. Esses erros foram calculados valendo-se do Método de White (White, 1980).

(b) Os termos $\left(^{*}\right),\left({ }^{* *}\right)$ e $\left(^{* * *}\right)$ denotam significância estatística dos coeficientes estimados aos níveis de $10 \%, 5 \%$ e $1 \%$, respectivamente.

ciente de determinação ajustado de cada especificação estimada $\left(R^{2}\right)$, bem como o número de observações das amostras consideradas $(N) .{ }^{26}$

Os resultados econométricos reportados na Tabela 10 demonstram que, quando considerada a amostra total, a distribuição de projetos de investimento comporta-se em acordo com a Lei de Pareto, mas não de acordo com a Lei de Zipf, uma vez que o coeficiente estima- do fica em torno de -0,57. Resultados nos mesmos moldes são obtidos para os estratos da amostra que contêm os cinco e os dez maiores projetos de investimento, cujos coeficientes estimados equivalem a $-0,83$ e $-0,89$, respectivamente.

Embora possam estar condicionados ao tamanho relativamente pequeno desses estratos, esses resultados apontam para a inadequação da Lei de Zipf a esses conjuntos de dados. Por outro la- 
do, pode-se notar que, no caso dos estratos que encerram os 25,50 e 100 maiores projetos de investimento da amostra, se obtêm resultados que tendem a confirmar a ocorrência da Lei de Zipf, visto que os coeficientes estimados assumem valores próximos à unidade $(-1,07,-1,14$ e -1 , respectivamente), sendo estatisticamente significativos ao nível de $1 \%$.

Em termos gerais, esses resultados demonstram que, apesar de a amostra como um todo não seguir a Lei de Zipf, estratos que contêm a maior parte da amostra se adéquam empiricamente a essa lei, fato corroborado pelos valores relativamente elevados do coeficiente de determinação $\left(R^{2}\right)$ ajustado no caso de todas as especificaçôes consideradas.

O Gráfico 8 contém a evolução temporal dos coeficientes estimados para distintos estratos. De acordo com esse gráfico, nota-se que, embora menores estratos e o total da amostra náo confirmem a ocorrência da Lei de Zipf, essa lei acaba sendo confirmada para estratos que contêm entre 25 e 100 maiores projetos, que apresentam valores para os coeficientes estimados próximos à unidade.

Outra possível forma de estimação relacionada à Lei de Zipf equivale a uma especificação quadrática nos seguintes moldes:

$$
\begin{aligned}
\ln (\text { rank })= & \alpha-\zeta \ln (\text { valor de investimentos })+ \\
& +\eta \ln (\text { valor de investimentos })^{2}+\varepsilon
\end{aligned}
$$

De acordo com essa fórmula, a posição dos projetos de investimento no ranking (rank) dependeria não apenas dos valores desses investimentos, mas também de seus valores ao quadrado. No caso, um valor de $\eta>0$ indicaria a ocorrência de uma distribuiçấo convexa (sobredimensionamento de maiores e menores projetos, em detrimento de projetos de tamanho médio), ao passo que um valor de $\eta<0$ indicaria a ocorrência de uma distribuição côncava (sobredimensionamento de projetos médios). Em última instância, essa especificação buscaria captar efeitos não lineares dos valores dos investimentos sobre suas respectivas posiçóes no ranking. Os resultados desse experimento estão contidos na Tabela 11.

De acordo com os resultados reportados, nota-se que, em relação à amostra total, tanto o coeficiente estimado para $\zeta$ quanto para $\eta$ apresentam valores negativos e estatisticamente distintos da unidade $(-0,308$ e $-0,046$, respectivamente). A princípio, esses resultados apontam para uma caracterização da distribuição de investimentos como côncava, havendo sobredimensionamento de pro- 
Gráfico 8_Evolução temporal dos coeficientes estimados para diferentes estratos dos projetos de investimento previstos para o Estado do Espírito Santo, 2009 a 2014

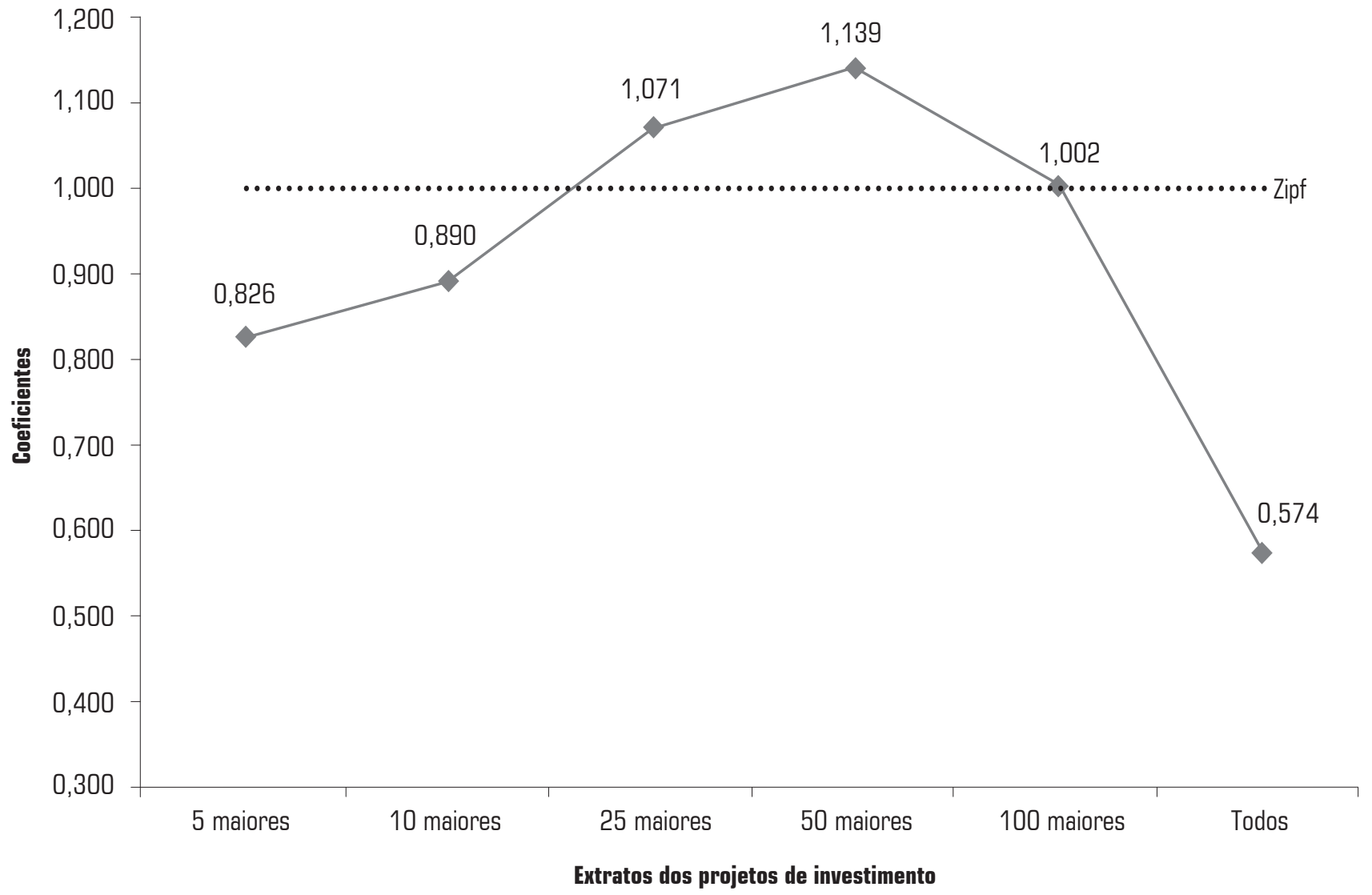

Fonte: Cálculos dos autores.

27 Para mais detalhes a esse respeito, ver a seção de testes de robustez do presente trabalho. jetos de tamanho médio e subdimensionamento de projetos maiores e menores. Por outro lado, quando da análise das estimativas referentes a outros estratos da amostra, nota-se que os resultados obtidos não são robustos. Em particular, os coeficientes estimados para $\zeta$ ultrapassam a unidade em alguns casos (25 e 50 maiores projetos), chegando até a assumir valores positivos em outros ( 5 maiores). ${ }^{27}$ 
Tabela 11_Coeficientes estimados para a equação (7) - Espírito Santo, 2009 a 2014

\begin{tabular}{|c|c|c|c|c|}
\hline Estratos & $\zeta$ & $\eta$ & $\mathbf{R}^{2}$ ajustado & $N$ \\
\hline 5 maiores & $\begin{array}{c}2,087 \\
(5,035)\end{array}$ & $\begin{array}{l}-0,174 \\
(0,300)\end{array}$ & 0,880 & 5 \\
\hline 10 maiores & $\begin{array}{l}-1,644 \\
(1,443)\end{array}$ & $\begin{array}{c}0,047 \\
(0,090)\end{array}$ & 0,960 & 10 \\
\hline 25 maiores & $\begin{array}{c}-3,528^{* * *} \\
(0,558)\end{array}$ & $\begin{array}{l}0,163^{* * *} \\
(0,038)\end{array}$ & 0,985 & 25 \\
\hline 50 maiores & $\begin{array}{c}-2,018^{* * *} \\
(0,269)\end{array}$ & $\begin{array}{c}0,063^{* * *} \\
(0,019)\end{array}$ & 0,976 & 50 \\
\hline 100 maiores & $\begin{array}{l}-0,285 \\
(0,251)\end{array}$ & $\begin{array}{c}-0,058^{* * *} \\
(0,022)\end{array}$ & 0,977 & 100 \\
\hline Todos & $\begin{array}{c}-0,308^{* * *} \\
(0,010)\end{array}$ & $\begin{array}{c}-0,046^{* * *} \\
(0,002)\end{array}$ & 0,993 & 972 \\
\hline
\end{tabular}

Fonte: Cálculos dos autores.

Notas:

(a) Erros-padrão das estimativas reportadas entre parênteses. Esses erros foram calculados

com base no Método de White (White, 1980).

(b) Os termos $\left({ }^{*}\right),\left({ }^{* *}\right)$ e $\left(^{* * *}\right)$ denotam significância estatística dos coeficientes estimados aos níveis

de $10 \%, 5 \%$ e $1 \%$, respectivamente.

Finalmente, o Gráfico 9 busca averiguar o ajustamento da Lei de Zipf à distribuição de projetos de investimento do Espírito Santo. Em relação a este gráfico, são expostas duas curvas distintas: uma referente a uma distribuição correspondente exatamente àquela proposta originalmente por Zipf (linha tracejada) e ou- tra correspondente à distribuição efetiva dos projetos de investimento do Estado.

Verificando o gráfico, pode-se notar que a distribuição efetiva de projetos de investimento apresenta-se como superior à distribuição de Zipf quando se trata de amostras que contêm até 100 projetos de investimentos aproximadamente, 
Gráfico 9_Valor dos investimentos previstos e Lei de Zipf - Espírito Santo - 2009 a 2014

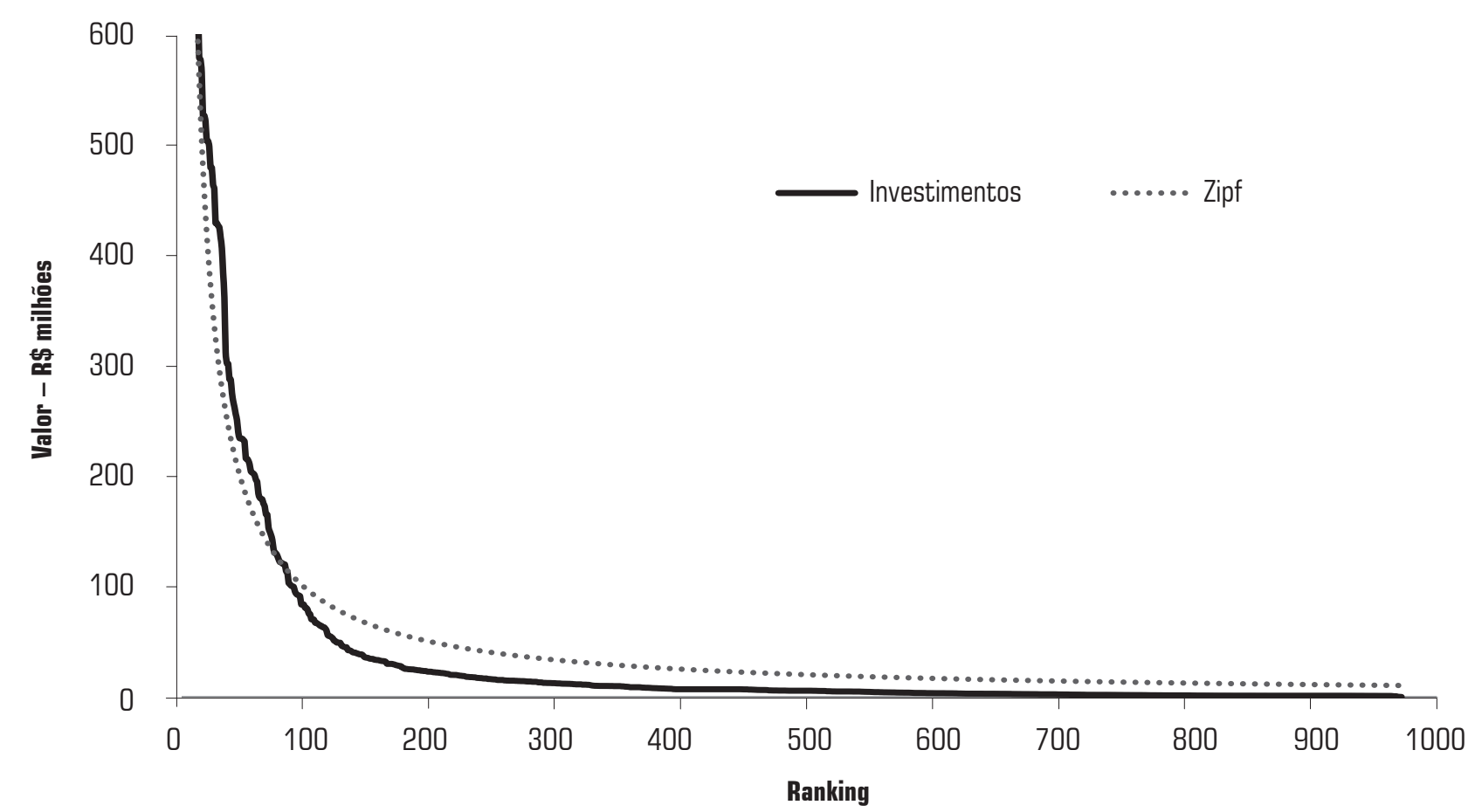

Fonte: Cálculos dos autores.

${ }^{28}$ Seria interessante a

elaboração de um modelo teórico nos moldes de Gabaix (1999), capaz de explicar esse padrão empírico. Desde já, fica a sugestão de pesquisa futura nesses moldes. com esse padrão sendo revertido para projetos situados em maiores posiçóes no ranking. Uma decorrência básica desse resultado equivale a um sobredimensionamento dos projetos de maior valor em relação aos de menor valor, em relação aos 100 maiores projetos.

Por outro lado, quando é considerado o tamanho de amostras superiores a
100 projetos, nota-se um padrão oposto, no qual ocorre um subdimensionamento de projetos de maior valor. Essa mudança no perfil da distribuição de projetos de investimento, à medida que novos projetos são adicionados à amostra, pode equivaler à razão pela qual a Lei de Zipf tende a ser válida para alguns estratos específicos da amostra, apenas. ${ }^{28}$ 


\section{7_ Testes de robustez ${ }^{29}$}

Nesta seção são reportados resultados de testes realizados para checar a robustez dos principais resultados obtidos anteriormente. Basicamente, conduz-se um teste de robustez relacionado a um método de estimação alternativo ao original, empregado no caso de distribuiçóes de cauda longa. A intenção básica desse teste equivale a verificar se os resultados anteriores são mantidos sob especificações alternativas.

Conforme dito anteriormente, as estimativas relacionadas a distribuiçóes de cauda longa nos moldes de distribuiçôes de Pareto e Zipf citadas acima foram obtidas baseando-se no Método de Mínimos Quadrados Ordinários (MMQO). Uma vantagem relacionada a esse método equivale a sua relativa simplicidade. Entretanto, há a possibilidade de ocorrência de severos vieses em estimaçóes desse tipo relacionadas a distribuiçóes de cauda longa, especialmente quando se trata de amostras pequenas.

Por conta dessa limitação do método supracitado, Gabaix e Ibragimov (2011) propuseram um método alternativo de estimação, correspondente à seguinte especificação: $\ln \left(\mathrm{N}\left(\mathrm{n}_{\mathrm{i}}\right)-0,5\right)=\ln \mathrm{A}-\zeta \ln (n)_{\mathrm{i}}+\varepsilon_{1}$

Ou seja, em se tratando da especificação proposta, subtrai-se 0,5 do rank dos projetos de investimento na distribuiçãao. Segundo os autores, o método proposto, além de reduzir o viés inerente a amostras pequenas, apresenta vantagens em relação ao MMQO, mesmo no caso de distribuiçóes de cauda longa que exibam diferenças em relação a leis de potência. Por conta disso, optou-se pela estimação da forma funcional derivada com base nesse método. Os resultados estão contidos na Tabela 12.

Uma análise dos resultados reportados na Tabela 12 permite constatar que, quando se aborda o método de estimação proposto por Gabaix e Ibragimov (2011), as estimativas obtidas apresentam magnitudes superiores àquelas obtidas anteriormente. Em particular, vale notar que, apesar de não ocorrer diferença significativa no que diz respeito ao coeficiente estimado para a amostra como um todo (que passa de -0,574 para-0,579), todos os demais coeficientes relacionados a estratos específicos da amostra sofrem elevação em suas respectivas magnitudes, com valores superiores à unidade, em geral.
${ }^{29}$ Os autores agradecem a um parecerista anônimo por sugerir uma seção nesses moldes. 
Tabela 12_Robustez: coeficientes estimados para a equação (8) - Espírito Santo, 2009-2014

\begin{tabular}{|c|c|c|c|}
\hline Estratos & $\zeta$ & $\mathbf{R}^{2}$ ajustado & $N$ \\
\hline 5 maiores & $\begin{array}{c}-1,128^{* * *} \\
(0,164)\end{array}$ & 0,907 & 5 \\
\hline 10 maiores & $\begin{array}{c}-1,113^{* * *} \\
(0,089)\end{array}$ & 0,962 & 10 \\
\hline 25 maiores & $\begin{array}{c}-1,235^{* * *} \\
(0,054) \\
\end{array}$ & 0,978 & 25 \\
\hline 50 maiores & $\begin{array}{c}-1,252^{* * *} \\
(0,037)\end{array}$ & 0,98 & 50 \\
\hline 100 maiores & $\begin{array}{c}-1,060^{* * *} \\
(0,032) \\
\end{array}$ & 0,966 & 100 \\
\hline Todos & $\begin{array}{c}-0,579^{* * *} \\
(0,012)\end{array}$ & 0,953 & 972 \\
\hline
\end{tabular}

Fonte: Cálculos dos autores.

Notas:

(a) Erros-padrăo das estimativas reportadas entre parênteses. Esses erros foram calculados com base no Método de White (White, 1980).

(b) Os termos ${ }^{(*)},\left(^{* *}\right)$ e $\left.{ }^{(* *}\right)$ denotam significância estatística dos coeficientes estimados aos níveis de $10 \%, 5 \%$ e $1 \%$, respectivamente.

Nesse caso, a interpretação referente a coeficientes cujos valores são maiores que um implica que, em termos de hierarquia de valores, haveria maior igualdade entre maiores e menores projetos de investimento. Mais uma vez, vale notar a ocorrência de diferenças entre resultados referentes à amostra como um todo e a es- tratos específicos dessa. Ainda assim, em termos qualitativos, os resultados obtidos tendo por base esse exercício confirmam os resultados anteriores, conforme pode ser comprovado no Gráfico 10, que expóe a evolução temporal dos coeficientes estimados, comparando-os com os coeficientes obtidos via MMQO. 
Gráfico 10_Robustez: evolução temporal dos coeficientes estimados para distintos estratos da distribuição de projetos de investimento previstos - Espírito Santo, 2009-2014

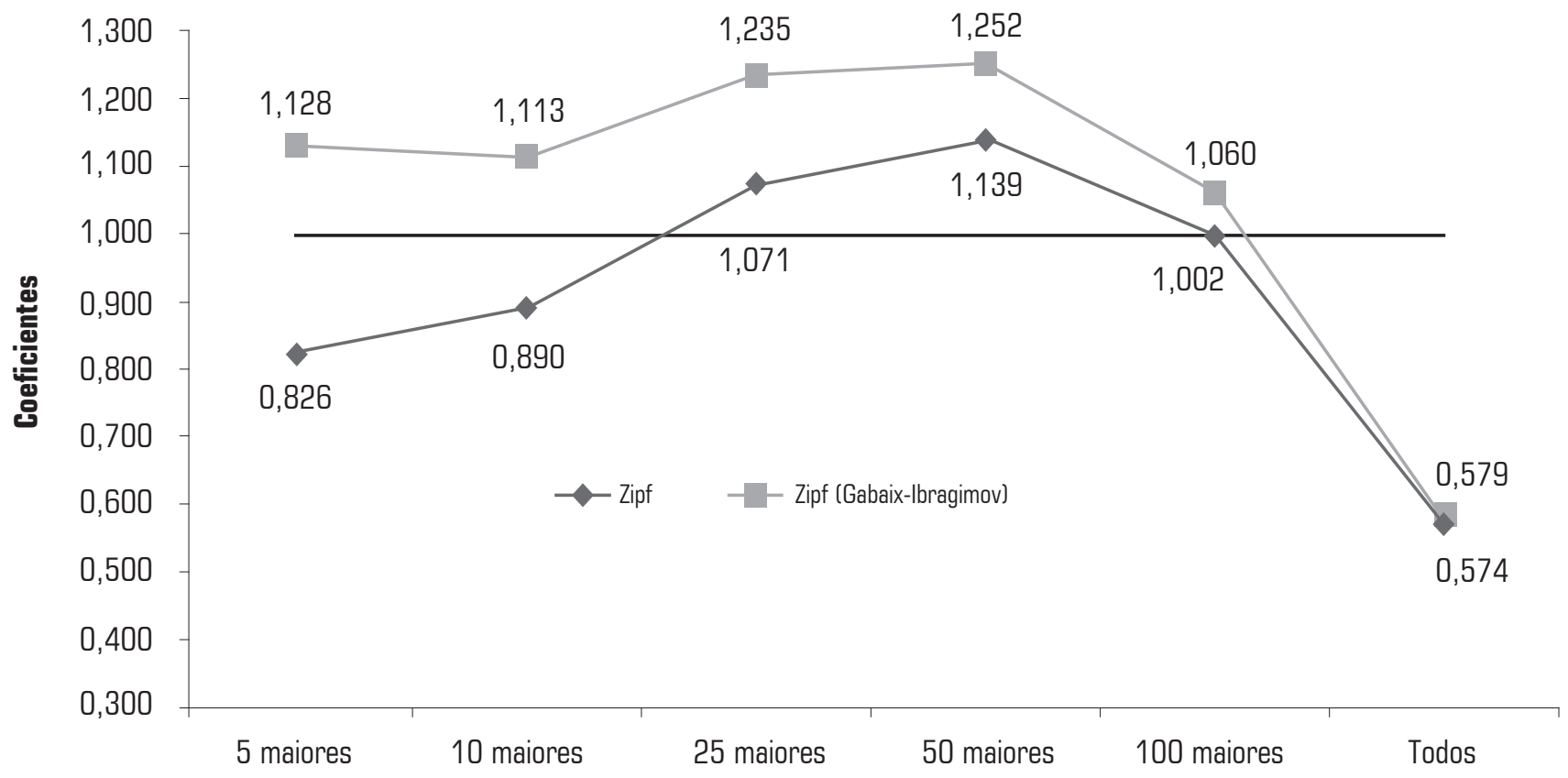

Estratos dos projetos de investimentos

Fonte: Cálculos dos autores.

A Tabela 13, por sua vez, contém resultados relacionados à estimação de formas funcionais quadráticas com base no método proposto por Gabaix e Ibragimov (2011).

Similarmente ao caso anterior, nota-se que os resultados obtidos, além de não serem robustos, apresentam sinais e magnitudes contraintuitivos. Se, por um lado, esses resultados denotam falta de robustez das estimativas anteriores, por outro, demonstram que a distribuição de investimentos previstos para o Estado do Espírito Santo talvez não possa ser modelada a partir de uma especificação quadrática. Ainda assim, há de se notar que, 
Tabela 13_Robustez: coeficientes estimados para a equação (7) pelo Método de Gabaix-Ibragimov Espírito Santo, 2009-2014

\begin{tabular}{|c|c|c|c|c|}
\hline Estratos & $\zeta$ & $\eta$ & $\mathbf{R}^{2}$ ajustado & $N$ \\
\hline 5 maiores & $\begin{array}{l}7,082 \\
(6,315)\end{array}$ & $\begin{array}{l}-0,491 \\
(0,376)\end{array}$ & 0,880 & 5 \\
\hline 10 maiores & $\begin{array}{l}-0,011 \\
(1,808)\end{array}$ & $\begin{array}{l}-0,069 \\
(0,113)\end{array}$ & 0,960 & 10 \\
\hline 25 maiores & $\begin{array}{c}-2,524^{* * *} \\
(0,728)\end{array}$ & $\begin{array}{c}0,086 \\
(0,050)\end{array}$ & 0,985 & 25 \\
\hline 50 maiores & $\begin{array}{c}-1,337^{* * *} \\
(0,305)\end{array}$ & $\begin{array}{c}0,006 \\
(0,022)\end{array}$ & 0,976 & 50 \\
\hline 100 maiores & $\begin{array}{c}0,127 \\
(0,209)\end{array}$ & $\begin{array}{c}-0,096^{* * *} \\
(0,018)\end{array}$ & 0,977 & 100 \\
\hline Todos & $\begin{array}{c}-0,294^{* * *} \\
(0,011)\end{array}$ & $\begin{array}{c}-0,050^{* * *} \\
(0,002)\end{array}$ & 0,993 & 972 \\
\hline
\end{tabular}

Fonte: Cálculos dos autores.

Notas:

(a) Erros-padrão das estimativas reportadas entre parênteses. Esses erros foram calculados com base no Método de White (White, 1980).

(b) Os termos $\left({ }^{*}\right),\left({ }^{* *}\right)$ e $\left.{ }^{(* *}\right)$ denotam significância estatística dos coeficientes estimados aos níveis de $10 \%, 5 \%$ e $1 \%$, respectivamente.

em se tratando da amostra total, os resultados qualitativos tendem a ser confirmados em relação a esse método alternativo de estimação. De qualquer forma, a verificação adicional desse resultado fica como tema de pesquisa futura.

\section{8_Conclusões e agenda de pesquisa futura}

Por conta de suas características específicas, o investimento agregado representa uma das mais importantes variáveis no processo de desenvolvimento de uma localidade. Este trabalho buscou realizar 
uma caracterização empírica da distribuição de projetos de investimento planejados para o Espírito Santo, no período 2009-2014, com ênfase no caráter assimétrico dessa distribuição, assim como sua adequação em relação a uma distribuição de cauda longa nos moldes das Leis de Pareto e Zipf.

Os principais resultados obtidos a partir desse esforço de pesquisa foram os seguintes:

i. A distribuição dos projetos de investimento previstos para o Estado apresenta-se como nitidamente assimétrica;

ii. Essa distribuição segue um formato de "cauda longa", qualquer que seja o estrato de amostra considerado;

iii. Em termos de participação relativa, os 25, 50 e 100 maiores projetos de investimento previstos para o Estado respondem, respectivamente, por $60 \%, 74 \%$ e $86 \%$ do total da amostra;

iv. Não há resultados robustos relacionados a possíveis padrôes de concavidade ou convexidade da distribuição;

v. Apesar do formato da distribuição dos projetos de investimento, a amostra total não pode ser caracterizada com base na Lei de Zipf, com essa lei sendo válida apenas para alguns estratos específicos

Esses resultados são interessantes por confirmarem a ocorrência de regularidades empíricas verificadas em outros contextos para os projetos de investimento previstos para o Estado do Espírito Santo. Por um lado, os resultados obtidos são robustos à utilização de métodos alternativos de estimação, criados especialmente para lidar com distribuiçóes de cauda longa (Gabaix; Ibragimov, 2011). Por outro, vale a ressalva de que esses resultados não são robustos no caso de utilização de formas funcionais não lineares, conforme demonstrado acima.

Em termos aplicados, os resultados obtidos ressaltam que uma parcela relativamente pequena dos projetos considerados responde pela maior parte da distribuição analisada, fato que reforça o caráter assimétrico dessa distribuição. Adicionalmente, esses resultados demonstram que o estudo de estratos específicos dessa distribuição pode revelar alguns dos principais padróes da amostra como um todo, algo útil quando se fala de estudos aplicados, por exemplo. Em particular, dado o atual cenário de concentração espacial desses projetos (Iglesias, 2010; Magalhães; Toscano, 2011a), faz-se necessá- 
ria a criação de mecanismos capazes de incentivar a difusão de maior número de projetos em outras microrregiôes do Estado, como forma de se obter maior eficácia em relação à meta de Interiorização do Desenvolvimento, em conformidade com o Plano ES 2025 (SEP, 2006).

Algumas sugestóes no sentido de acelerar esse processo equivaleriam basicamente a um aumento do grau de diversificação das atividades econômicas desenvolvidas atualmente no Estado. Uma possibilidade nesse sentido equivaleria à identificação precisa dos Arranjos Produtivos Locais (APLs) existentes no Espírito Santo nos moldes propostos por Crocco et al. (2003), por exemplo, assim como a elaboração de um plano de desenvolvimento desses arranjos, conforme as sugestôes contidas em Felipe, Villaschi Filho e Oliveira (2010) para o caso espírito-santense.

Em termos de pesquisa futura, ficam três sugestões básicas. Em primeiro lugar, uma vez que os montantes relacionados aos projetos de investimento previstos podem ser estratificados de acordo com os municípios aos quais são destinados, poder-se-ia, a princípio, testar a ocorrência de transbordamentos espaciais desses investimentos (e.g., Leite; Magalhães, 2012; Leite; Silva, 2010) como forma de checar, em um primei- ro momento, a possível ocorrência de externalidades relacionadas a esses. A vantagem de um esforço de pesquisa nesses moldes equivale à possibilidade de governos locais estimularem o desenvolvimento de potencialidades em localidades específicas a partir de investimentos em áreas próximas geograficamente.

Em segundo lugar, seria interessante a realização de estudos que buscassem relacionar projetos de investimento com impactos sobre níveis de emprego de localidades específicas. Embora já existam tentativas nesse sentido (Araújo; Reisen, 2010), a estimação de elasticidades relacionando investimento e emprego pode ser de extrema valia para a elaboração e avaliação de programas de treinamento de mão de obra, por exemplo.

Em terceiro lugar, dados os resultados de testes de robustez reportados, fica a sugestão de utilização de métodos de estimação e/ou formas funcionais alternativos relacionados a distribuiçóes assimétricas, especialmente em se tratando de investimentos previstos em escala regional. A título de exemplo, a utilização do método proposto por Gabaix e Ibragimov (2011), no caso de estimaçóes envolvendo distribuiçóes de cauda longa, pode ser muito útil nesse sentido.

A existência de regularidades empíricas referentes a investimentos regio- 
nais pode revelar importantes padróes relacionados ao desenvolvimento de uma localidade. Por sua vez, esses padrôes podem ser úteis no diagnóstico de relevantes questóes socioeconômicas, relacionadas à formulação e implementação de políticas de incentivo a esses investimentos. O presente trabalho pode ser visto como uma tentativa inicial de registro de alguns desses padróes. Mais trabalho será necessário no sentido de se identificar novos resultados e explicar os padróes previamente reportados. Espera-se que, a partir desse esforço de pesquisa inicial, seja possível fornecer a base necessária para a compreensão da dinâmica do investimento no tempo e no espaço. 


\section{Referências bibliográficas}

ADAMIC, L. A. Zipf, power-laws, and Pareto: A ranking tutorial. Information Dynamics Labs, manuscrito, 2002.

ANDRADE, T. A.; SERRA, R. $V$. O recente desempenho das cidades médias no crescimento populacional urbano brasileiro. Texto para Discussão n. 554, IPEA mar.1998, $30 \mathrm{p}$.

ARAÚJO, E. R.; REISEN, V. A. Relação entre investimentos e o número de empregos gerados por empresas no Espírito Santo: Aplicação da metodologia de regressão não-paramétrica. In: ENCONTRO DE ECONOMIA DO ESPÍRITO SANTO, 1. 2010, Vitória. Anais... Vitória, 2010. 20 p.

BRITTO, G. Determinantes do investimento das firmas industriais brasileiras: Uma análise exploratória com modelos hierárquicos. Texto para Discussão n. 406, Cedeplar/UFMG, out. 2010. 23 p.

CABALLERO, R. Aggregate investment: Lessons from the previous millenium. American Economic Association Session, mimeo., Jan. 2000.
CAÇADOR, S. B.; GRASSI, R. A. Olhar crítico sobre o desempenho recente da economia capixaba: Uma análise a partir da literatura de desenvolvimento regional e de indicadores de inovação. Revista Econômica do Nordeste, v. 40, n. 3, p. 453-480, jul./set. 2009.

\section{CONJUNTURA \\ ECONÔMICA. Nova}

ferramenta para acompanhar os ciclos econômicos brasileiros. Conjuntura Econômica, v. 63, n. 6, p.30-32, jun. 2009.

CROCCO, M. A.; GALINARI, R.; SANTOS, F.; LEMOS, M. B.; SIMÓES, R. Metodologia de identificaçấo de arranjos produtivos locais potenciais. Texto para Discussão n. 212, Cedeplar/UFMG, jul. 2003. 28 p.

Di GIOVANNI, J.;

LEVCHENKO, A. A.;

RANCIÈRE, R. Power laws in firm size and openness to trade: Measurement and implications. University of Michigan, manuscrito, Mar. 2010. 29 p.

EASTERLY, W.; RESHEF,

A. Big hits in manufacturing exports and development. NYU, manuscrito, Oct. 2009. 49 p.
FELIPE, E. S.; VILLASCHI FILHO, A.; OLIVEIRA, U. J.

Das vantagens comparativas à criação de competências: $\mathrm{A}$ dinâmica dos arranjos produtivos locais no Espírito Santo e a centralidade do conhecimento e do aprendizado. In: ENCONTRO NACIONAL DA ASSOCIAÇÃO BRASILEIRA DE ESTUDOS REGIONAIS E URBANOS (ABER), 8., 2010, Juiz de Fora. Anais... Juiz de Fora, 2010, 24 p.

GABAIX, X. Zipf's Law for cities: An explanation. Quarterly Journal of Economics, v. 114, n. 3 , p. 739-767, Aug.1999.

GABAIX, X. Power laws. In: DURLAUF, S. N.; BLUME, L. E. (Eds.). The New Palgrave Dictionary of Economics, Second Edition. London: McMillan, 2008.

GABAIX, X.; IBRAGIMOV, R. Rank $-1 / 2$ : a simple way to improve the OLS estimation of tail exponents. Journal of Business Economics and Statistics, v. 29, n. 1, p. 24-39, Jan. 2011.
GABAIX, X.; IOANNIDES,

Y. M. The evolution of city size distributions. In: HENDERSON, J. V.; THISSE, J. F. (Eds.). Handbook of Urban and Regional Economics, Vol. IV, Chap. 53: Cities and Geography, p. 23412378, 2004

IGLESIAS, R. Análise dos grandes projetos de investimento no Espírito Santo. In: VESCOVI, A. P. V.; BONELLI, R. (Orgs.). Espirito Santo: Instituições, desenvolvimento e inclusão social. Vitória: IJSN, 2010. p. 165-218.

IOANNIDES, Y. M.; OVERMAN, H. G. Zipf's Law for cities: An empirical examination. Regional Science and Urban Economics, v. 33, n. 1, p. 127-137, 2003.

JARQUE, C. M.; BERA, A. K. A test for normality of observations and regression residuals.

International Statistical Review, v. 55, n. 1, p. 163-172, 1987.

LEAHY, J. V.; WHITED, T. $M$. The effect of uncertainty on investment: Some stylized facts. Journal of Money, Credit and Banking, v. 28, n. 1, Jan.1995. 
LEITE, L.M.; MAGALHÃES, M.A. Desigualdades intraestaduais no Espírito Santo: uma abordagem espacial exploratória. Revista de Economia (UFPR), v.38, n.1 (36), p.55-92, Jan.-Abr.2012.

LEITE, L. M.; SILVA, S.

P. Transbordamentos de pobreza entre municípios do Espírito Santo e seus vizinhos para outros estados. In: CONFERÊNCIA NACIONAL DE POLÍTICAS PÚBLICAS CONTRA A POBREZA E A DESIGUALDADE, 1., 2010 , Natal. Anais... Natal, 2010. 18 p.

LUPORINI, V.; ALVES, J. Investimento privado: Uma análise empírica para o Brasil.

Economia e Sociedade, v. 19, n. 3 p. 449-475, dez. 2010

MAGALHÂES, M. A. Preços de commodities e nível de atividade em uma pequena economia aberta: evidências empíricas para o estado do Espírito Santo. Economia e Sociedade, v.20, n.3 (43), p.533-566, Dez.2011.

MAGALHĀES, M. A.; RIBEIRO, A. P. L. Fatos estilizados dos ciclos de negócios no estado do Espírito Santo: uma abordagem quantitativa. Revista Econômica do Nordeste, v.42, n.3, p.597-620, Jul.-Set.2011.

MAGAlHÁES, M. A.; TOSCANO, V. N. Grau de abertura da economia do estado do Espírito Santo no período $1^{\circ}$ trim./04 - 2o trim./09. Indicadores Econômicos FEE, v.37, n.4, p.225-240, 2010 (2010a).
MAGALHĀES, M. A.; TOSCANO, V. N. Um estudo estatístico da distribuiçăo de investimentos previstos no Espírito Santo, 2009-2014. Nota Técnica n. 15, IJSN, dez. 2010, 27 p. (2010b)

\section{MAGALHĀES, M. A.;}

TOSCANO, V. N. Medindo a concentração de investimentos regionais: o caso do estado do Espírito Santo. Planejamento e Políticas Públicas, v.36, n.1, p.145170, Jan.-Jun.2011 (2011a).

MAGALHÃES, M.A.; TOSCANO, V.N. Hierarquia Urbana e Polarização Populacional: um estudo a partir de cidades do Espírito Santo. In: FERRARI, M. A. R.; ARTHMAR, R. (Orgs.). Novas Leituras sobre a Economia do Espírito Santo. Vitória: PPGEco/CORECON-ES, 2011, p.121-146 (2011b).

MANKIW, N. G.; ROMER, D. H.; WEIL, D. N. A contribution to the empirics of economic growth. Quarterly Journal of Economics, v. 107, n. 2, p. $407-$ 437, May 1992.

MIRANDA, R. A.; BADIA, B. D. A evolução da distribuição do tamanho das cidades de Minas Gerais: 1920-2000. In: SEMINÁRIO SOBRE A ECONOMIA MINEIRA, 12., 2006, Diamantina. Anais... Diamantina, 2006. 18 p.

NITSCH, V. Zipf zipped. Journal of Urban Economics, v. 57, n. 1, p. 86-100, 2005
OLIVEIRA, A. Petróleo e desenvolvimento: Oportunidades e desafios para o Espírito Santo. In: VESCOVI, A. P. V.; BONELLI, R. (Orgs.). Espirito Santo: Instituições, desenvolvimento e inclusão social. Vitória: IJSN, 2010. p. 243-267.

OLIVEIRA, U. J.; VILLASCHI FILHO, A.; FELIPE, E. S.

Diversificação econômica e a consolidação de uma estrutura industrial e urbana: Alguns aspectos da economia capixaba nos anos 1980-2000. In:

ENCONTRO DE ECONOMIA DO ESPÍRITO SANTO, 1. 2010, Vitória. Anais... Vitória, 2010. 20 p.

\section{PANORAMA ECONOAMICO -} Espírito Santo 2009. IJSN, vários números.

PEREIRA, L. V.; MACIEL, D.

S. O comércio exterior do estado do Espírito Santo. In: VESCOVI, A. P. V.; BONELLI, R. (Orgs.). Espírito Santo: Instituiçōes, desenvolvimento e inclusão social. Vitória: IJSN, 2010. p. 95-137.

PESSOTI, G. C.; PESSOTI,

B. C. Uma análise da política de atração de investimentos industriais da Bahia com especial referência ao Recôncavo Baiano no período de 2000 a 2004. ENCONTRO DE ECONOMIA BAIANA, 4., 2008, Salvador. Anais... Salvador, 2008 p. 171-186.
PIRES, A. A indústria do petróleo e o caso do Espírito Santo. In: VESCOVI, A. P. V.; BONELLI, R. (Orgs.). Espírito Santo: Instituiçóes, desenvolvimento e inclusão social. Vitória: IJSN, 2010. p. 219-242.

PUGA, F.; MEIRELLES, B.

Perspectivas de investimento na indústria em 2010-2013. Visäo do Desenvolvimento n. 79, BNDES, 15 mar. 2010. 8p.

RUIZ, R. M. Estruturas urbanas comparadas: Estados Unidos e Brasil. Estudos Econômicos, v. 35, n. 4, p. 715-737, out./dez.2005.

\section{SECRETARIA DE ESTADO}

DE ECONOMIA E

PLANEJAMENTO (SEP). Plano de Desenvolvimento Espírito Santo 2025 (ES 2025) - Avaliação Estratégica do Espírito Santo e Elementos para a Visão de Futuro, abr. 2006.

SILVEIRA, A. C. B. M.

Determinantes de curto prazo dos investimentos privados: Evidência empírica para os estados brasileiros. IPE/USP, mimeo., 2005. 22p.

SOLOW, R. M. A contribution to the theory of economic growth. Quarterly Journal of Economics, v. 70, n. 1, p. 65-94, Feb. 1956.

SOO, K.T. Zipf's Law for cities: A cross country investigation. Regional Science and Urban Economics, v. 35, n. 3, p. 239-263, May 2005. 
SOUZA, N. J. Abertura comercial e crescimento dos estados brasileiros, 1991/2000.

Teoria e Evidência Econômica, v. 11, n. 21, p. 41-61, nov. 2003.

TAVEIRA, A. M. A.; PELA,

A. C. A. S.; MARÇAL, C.

P.; MAGALHÃES, M. A.;

BRITTO, R. A. C.; TOSCANO,

$\mathrm{V}$. N. Investimentos previstos para o Espirito Santo: 2009-2014. Instituto Jones dos Santos Neves (IJSN). Vitória, Espírito Santo, jul. 2010.67 p.

WHITE, H. A

heteroskedasticity-consistent covariance matrix and a direct test for heteroskedasticity. Econometrica, v. 48, n. 4, p. $817-$ 838, 1980 .

ZIPF, G. Human behavior and the principle of least effort. Cambridge: Addison-Wesley, 1949.

O presente trabalho equivale a
uma versáo substancialmente
revisada de Magalhäes
e Toscano (2010b). Um
agradecimento especial a um
parecerista anônimo deste
periódico, por fornecer valiosas
sugestôes à versão anterior do
trabalho. Vale a ressalva de que
as opiniōes aqui contidas não
refletem as opiniōes do IJSN
ou de algum outro membro
dessa instituiçāo. Também
vale a ressalva usual de que
os erros e as idiossincrasias
remanescentes devem-se única e
exclusivamente aos autores.
E-mail de contato dos autores
matheus@isn.es.gov.br
victor.toscano@ijsn.es.gov.br

O presente trabalho equivale a uma versäo substancialmente agradecimento especial a um periódico, por fornecer valiosas sugestóes à versáo anterior do as opinióes aqui contidas não refletem as opinióes do IJSN ou de algum outro membro a instituicão. Também vale a ressalva usual de que os erros e as idiossincrasia remanescentes devem-se única e aprovado em fevereiro de 2011. 
Macrorregióes de Planejamento e Microrregióes

Apêndice A

Administrativas do Estado do Espírito Santo

O Quadro A1 apresenta as macrorregióes de planejamento e as microrregióes de gestão administrativa do Estado do Espírito Santo, assim como os municípios que as compóem.

Especificamente, a primeira coluna da tabela apresenta as macrorregióes, a segunda coluna apresenta as microrregióes e a terceira coluna contém os municípios correspondentes a cada regiáo considerada.
Quadro_A1_Macrorregiões de planejamento e microrregiões de gestão administrativa do Estado do Espírito Santo

\begin{tabular}{|c|c|c|}
\hline Macrorregião & Microrregião & Município \\
\hline \multirow{4}{*}{ 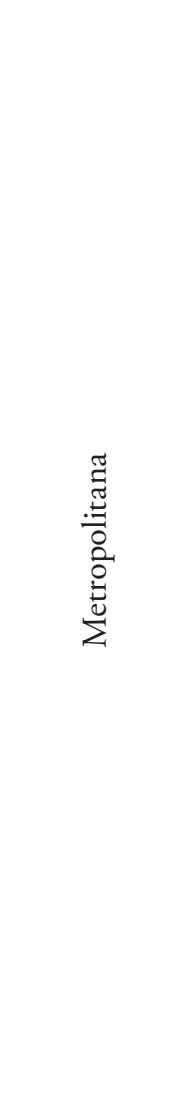 } & Central Serrana & $\begin{array}{c}\text { Itaguaçu } \\
\text { Itarana } \\
\text { Santa Leopoldina } \\
\text { Santa Maria de Jetibá } \\
\text { Santa Teresa } \\
\text { São Roque do Canaá }\end{array}$ \\
\hline & $\begin{array}{c}\text { Metrópole } \\
\text { Expandida Sul }\end{array}$ & $\begin{array}{l}\text { Alfredo Chaves } \\
\text { Anchieta } \\
\text { Iconha } \\
\text { Itapemirim } \\
\text { Marataízes } \\
\text { Piúma } \\
\end{array}$ \\
\hline & Metropolitana & $\begin{array}{c}\text { Cariacica } \\
\text { Fundão } \\
\text { Guarapari } \\
\text { Serra } \\
\text { Viana } \\
\text { Vila Velha } \\
\text { Vitória }\end{array}$ \\
\hline & Polo Linhares & $\begin{array}{c}\text { Aracruz } \\
\text { Ibiraçu } \\
\text { João Neiva } \\
\text { Linhares } \\
\text { Rio Bananal } \\
\text { Sooretama }\end{array}$ \\
\hline
\end{tabular}


Quadro_A1_Macrorregióes de planejamento e microrregióes de gestão administrativa do Estado do Espírito Santo

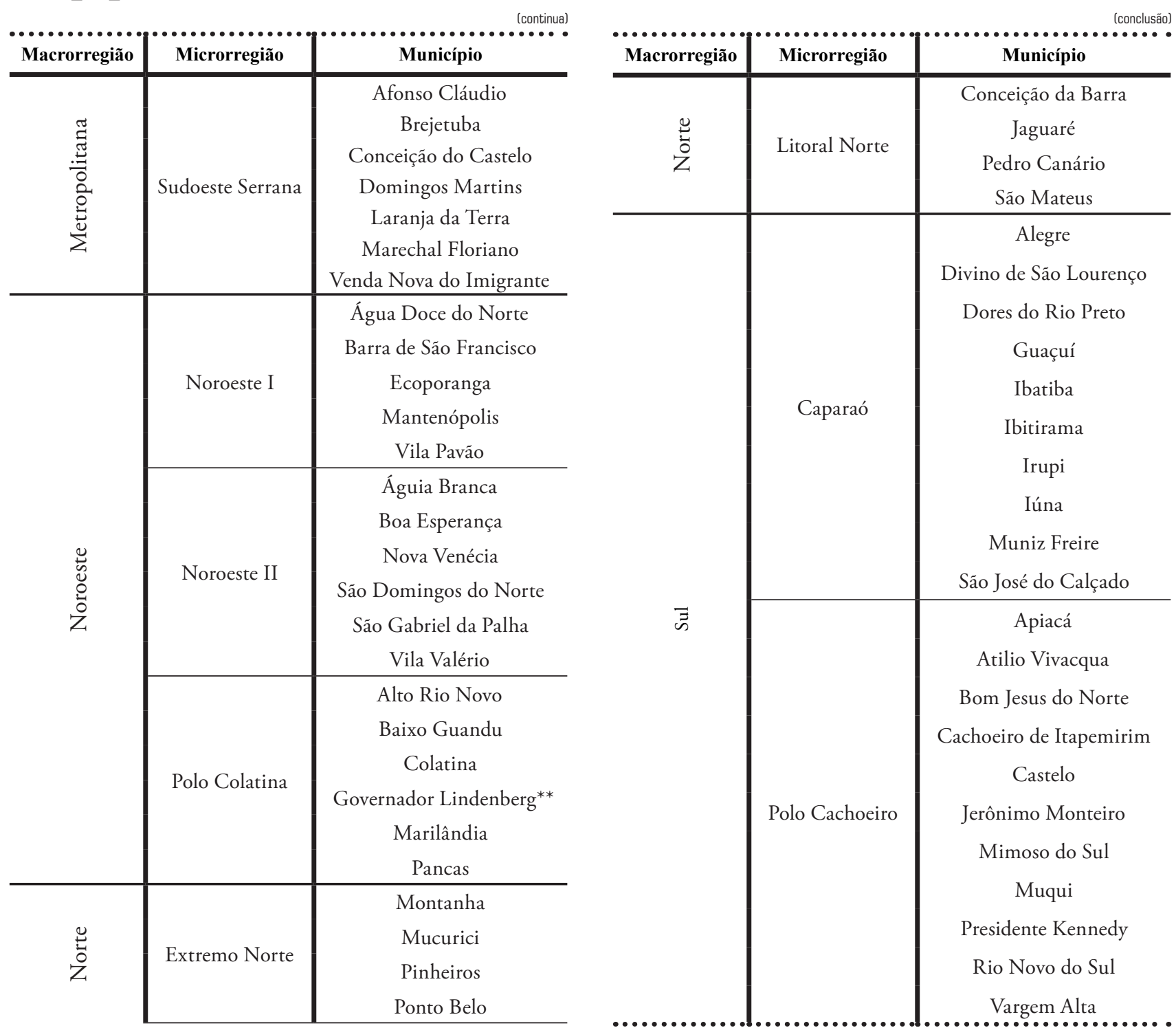

